Original article

\title{
Updated European Consensus Statement on diagnosis and treatment of adult ADHD
}

J.J.S. Kooijj ${ }^{a, b, *}$, D. Bijlenga ${ }^{\mathrm{a}}$, L. Salerno ${ }^{9}$, R. Jaeschke ${ }^{1}$, I. Bitter ${ }^{\mathrm{J}}$, J. Balázs $^{\mathrm{c}}$, J. Thome ${ }^{\mathrm{S}}$, G. Dom ${ }^{\mathrm{X}}$, S. Kasper ${ }^{\mathrm{d}}$, C. Nunes Filipe ${ }^{7}$, S. Stes ${ }^{\mathrm{e}}$, P. Mohr ${ }^{W}$, S. Leppämäki ${ }^{\mathrm{f}}$, M. Casas $^{g}$, J. Bobes ${ }^{\circ}$, J.M. Mccarthy ${ }^{\mathrm{h}}$, V. Richarte ${ }^{\mathrm{i}}$, A. Kjems Philipsen ${ }^{\mathrm{j}}$, A. Pehlivanidis $^{8}$, A. Niemela ${ }^{\mathrm{k}}$, B. Styr ${ }^{\mathrm{l}}$, B. Semerci ${ }^{10}$, B. Bolea-Alamanac ${ }^{\mathrm{m}}, \mathrm{D}$. Edvinsson ${ }^{\mathrm{n}}$, D. Baeyens $^{\mathrm{o}}$, D. Wynchank ${ }^{\mathrm{a}}$, E. Sobanski ${ }^{\mathrm{L}}$, A. Philipsen ${ }^{\mathrm{p}}$, F. McNicholas ${ }^{4}, \mathrm{H}_{\text {. Caci }}{ }^{\mathrm{M}}$, I. Mihailescu $^{\mathrm{q}}$, I. Manor ${ }^{3}$, I. Dobrescur ${ }^{\mathrm{r}}$, T. Saito ${ }^{\mathrm{H}}$, J. Krause ${ }^{5}$, J. Fayyad ${ }^{\mathrm{s}}$, J.A. Ramos-Quiroga ${ }^{\mathrm{N}}$, K. Foeken ${ }^{\mathrm{t}}$, F. Rad ${ }^{\mathrm{u}}$, M. Adamou ${ }^{\mathrm{v}}$, M. Ohlmeier ${ }^{6}$, M. Fitzgerald $^{\mathrm{w}}$, M. Gill ${ }^{\mathrm{Q}}$, M. Lensing $^{\mathrm{U}}$, N. Motavalli Mukaddes ${ }^{\mathrm{x}}$, P. Brudkiewicz ${ }^{\mathrm{y}}$, P. Gustafsson ${ }^{11}$, P. Tani $^{\mathrm{z}}$, P. Oswald ${ }^{12}$, P.J. Carpentier ${ }^{A}$, P. De Rossi ${ }^{Y}$, R. Delorme ${ }^{\mathrm{B}}$, S. Markovska Simoska ${ }^{\mathrm{C}}$, S. Pallanti $^{\mathrm{D}}$, , S. Young $^{\mathrm{E}}$, S. Bejerot ${ }^{V}$, T. Lehtonen ${ }^{\mathrm{F}}$, J. Kustow ${ }^{\mathrm{G}}$, U. Müller-Sedgwick ${ }^{\mathrm{K}}$, T. Hirvikoski ${ }^{\mathrm{Z}}$, V. Pironti ${ }^{2}$, Y. Ginsberg ${ }^{\mathrm{T}}$, Z. Félegyházy ${ }^{\mathrm{I}}$, M.P. Garcia-Portilla ${ }^{\mathrm{R}}$, P. Asherson ${ }^{\mathrm{P}}$

a PsyQ Psycho-Medical Programs, Expertise Center Adult ADHD, Carel Reinierszkade 197, 2593 HR, The Hague, The Netherlands

${ }^{\mathrm{b}}$ Amsterdam UMC, LocationVUMc, Dept. of Psychiatry, Amsterdam, the Netherlands

' Institute of Psychology, Eotvos Lorand University, Vadaskert Child Psychiatric Hospial and Outpatient Clinic, Budapest, Hungary

d Medical University Vienna, Department of Psychiatry and Psychotherapy, Vienna, Austria

e University Psychiatric Center, KU Leuven, Kortenberg, Belgium

${ }^{\mathbf{f}}$ Helsinki University Central Hospital, Department of Psychiatry, HUS, Finland

${ }^{g}$ Department of Psychiatry, Hospital Universitari Vall d'Hebron, Barcelona, Catalonia, Spain; Psychiatric Genetics Unit, Vall d'Hebron Research Institute (VHIR), Barcelona, Catalonia, Spain; Biomedical Network Research Centre on Mental Health (CIBERSAM), Barcelona, Catalonia, Spain; Department of Psychiatry and Forensic Medicine, Universitat Autònoma de Barcelona, Barcelona, Catalonia, Spain

h Visiting senior lecturer, King's College London, United Kingdom; Midland Regional Forensic Service, Hamilton, New Zealand

i Department of Psychiatry, Hospital Universitari Vall d'Hebron, Barcelona; Biomedical Network Research Centre on Mental Health (CIBERSAM), Barcelona;

Department of Psychiatry and Legal Medicine, Universitat Autònoma de Barcelona, Barcelona, Spain

${ }^{\mathrm{j}}$ DPC Naestved, Ladby, Naestved, Region Sjaelland, Denmark

${ }^{\mathrm{k}}$ Wellmind Terveys Oy, Oulu, Finland

${ }^{1}$ Mccabi Health Services (H.M.O), Tel Aviv, Israel

${ }^{\mathrm{m}}$ General Systems Division, Centre for Addiction and Mental Health/ Dept. Of Psychiatry, University of Toronto, Toronto, Canada

${ }^{n}$ Uppsala University, Uppsala University Hospital, Akademiska sjukhuset, Uppsala, Stockholm

o Parenting and Special Education, KU Leuven, Leuven, Belgium

P University of Bonn, Department of Psychiatry and Psychotherapy, Bonn, Germany

${ }^{\mathrm{q}}$ Alexandru Obregia Clinical Hospital of Psychiatry, Bucharest, Romania

${ }^{\mathrm{r}}$ University of Medicine and Pharmacy “Carol Davila". Child and adolescent Psychiatry Department, Prof. Dr. Alex Obregia”Psychiatry Hospital, Bucharest, Romania

s St George Hospital University Medical Center, Balamand University Faculty of Medicine, Institute for Development, Research, Advocacy and Applied Care, Department of Psychiatry and Clinical Psychology, St George Hospital, Achrafieh, Beirut, Lebanon

${ }^{\mathrm{t}}$ Vieux Chemin de Cagnes à La Gaude, la Gaude, France

"University of Medicine and Pharmacy "Carol Davila"; Child and adolescent Psychiatry Department, Prof. Dr. Alex Obregia"Psychiatry Hospital, Bucharest,

Romania

${ }^{v}$ University of Huddersfield and South West Yorkshire Partnership NHS, Manygates Clinic, Wakefield, England

${ }^{\mathrm{w}}$ Trinity College, Blanchardstown Village, Dublin, Republic of Ireland

${ }^{\mathrm{x}}$ Istanbul Institute of Child and Adolescent Psychiatry, Istanbul, Turkey

${ }^{\mathrm{y}}$ Centrum Dobrej Terapii, Cracow, Poland

${ }^{\mathrm{z}}$ Department of Psychiatry, Clinic for Neuropsychiatry, Helsinki University Central Hospital, HUS, Finland

${ }^{A}$ Reinier van Arkel Mental Health Institute,'s-Hertogenbosch, Netherlands

${ }^{\mathrm{B}}$ Child and Adolescent Psychiatry Department, Robert Debré Hospital, Paris, France

${ }^{\mathrm{C}}$ Macedonian Academy of Sciences and Arts, Skopje, Republic of Macedonia

D Stanford University Medical Center, University of Florence, INS Institute of Neuroscience, Florence, Italy

${ }^{E}$ Psychology Services Limited, Croydon, England

${ }_{\mathrm{F}}$ Neuropsykologkonsult Taina Lehtonen, Hjärup, Sweden

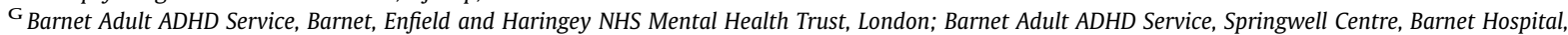
Barnet, England

${ }^{\mathrm{H}}$ Department of Child and adolescent Psychiatry, Graduate School of Medicine, Hokkaido University, North 15,West 7, Kita-ku, Sapporo, 060-8638 Japan 


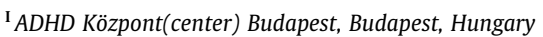

${ }^{\mathrm{J}}$ Semmelweis University, Department of Psychiatry, Budapest, Hungary

${ }^{\mathrm{K}}$ Adult ADHD Service, Barnet, Enfield \& Haringey NHS Mental Health Trust, North London \& Department of Psychiatry, University of Cambridge; Adult ADHD

Service, Springwell Centre / Barnet Hospital, Barnet, London, England

${ }^{\mathrm{L}}$ Central Institute of Mental Health, Mannheim; University Medical Center Mainz, Mainz, Germany

${ }^{\mathrm{M}}$ Hopitaux Pediatriques de Nice CHU Lenval, Nice, France

${ }^{\mathrm{N}}$ Department of Psychiatry, Hospital Universitari Vall d'Hebron, Barcelona, Catalonia, Spain; Psychiatric Genetics Unit, Vall d'Hebron Research Institute

(VHIR), Barcelona, Catalonia, Spain; Biomedical Network Research Centre on Mental Health (CIBERSAM), Barcelona, Catalonia, Spain; Department of

Psychiatry and Forensic Medicine, Universitat Autònoma de Barcelona, Barcelona, Catalonia, Spain

O Department of Psychiatry, School of Medicine, University of Oviedo - Centro de Investigación Biomédica and Red de Salud Mental, CIBERSAM, Oviedo, Spain

P SGDP Building, Institute of Psychiatry Psychology and Neuroscience, Kings' College London, London, England

${ }^{\mathrm{Q}}$ Department of Psychiatry, Trinity College Dublin, School of Medicine, Dublin, Republic of Ireland

${ }^{\mathrm{R}}$ Dept. of Psychiatry, University of Oviedo, School of Medicine, Psychiatry, Oviedo, Spain

s Thome, Klinik und Poliklinik für Psychiatrie und Psychotherapie, Universitatsmedizin Rostock, Rostock, Germany

${ }^{\mathrm{T}}$ Stockholm Center for Eating Disorder RED Unit, Department of Clinical Neuroscience, Karolinska Institutet, Stockholm, Sweden

U Oslo University Hospital, Department of Rare Disorders, NevSom - Norwegian Centre of Expertise for Neurodevelopmental Disorders and Hypersomnias,

Oslo, Norway

v Örebro Univerity, School of Medical Sciences, Campus USÖ, Örebro, Sweden

$\mathrm{w}^{\mathrm{N}}$ National Institute of Mental Health, Klecany, Czech Republic; Third Faculty of Medicine, Charles University Prague, Czech Republic

${ }^{\mathrm{X}}$ Antwerp University (UA, CAPRI), Boechout, Belgium

${ }^{Y}$ Department of Neurology and Psychiatry, Sapienza University of Rome, Rome; Department NSMOS, Faculty of Medicine and Psychology, University

"Sapienza"of Rome, Rome, Italy

${ }^{\mathrm{z}}$ Center for Neurodevelopmental Disorders at Karolinska Institutet (KIND), CAP Research Center, Stockholm, Sweden

${ }^{1}$ Jagiellonian University Medical College, Section of Affective Disorders, Department of Psychiatry, Krakow, Poland

${ }^{2}$ Cambridge Adult ADHD \& ASD Clinic, Cambridge, England

${ }^{3}$ Geha MHC, Petach-Tikva, Israel

${ }^{4}$ University College Dublin, Dublin, Republic of Ireland

${ }^{5}$ Outpatient Clinic, Ottobrunn, Germany

${ }^{6}$ Klinikum Kassel, Department of Psychiatry and Psychotherapy, Kassel, Germany

${ }^{7}$ Nova Medical School. Universidade NOVA Lisboa, Lisboa, Portugal

${ }^{8}$ National and Kapodistrian University of Athens Medical School, Eginition Hospital, Department of Psychiatry, Athens, Greece

${ }^{9}$ INS, Institute of Neuroscience, Florence, Italy

${ }^{10}$ Hasan Kalyoncu University, Poyraclk Sokak. Istanbul, Turkey

${ }^{11}$ Lund University, Clinical Sciences Lund, Child and Adolescent Psychiatry, Lund, Sweden

${ }^{12}$ High Security Hospital, CRP Les Marronniers, Tournai, Belgium

A R T I C L E I N F O

Article history:

Received 9 July 2018

Received in revised form 2 November 2018

Accepted 3 November 2018

Available online 16 November 2018

\section{Keywords:}

Adult ADHD

Updated European Consensus Statement

Diagnosis

Treatment

European Network Adult ADHD

EPA

\section{A B S T R A C T}

Background Attention-deficit/hyperactivity disorder (ADHD) is among the most common psychiatric disorders of childhood that often persists into adulthood and old age. Yet ADHD is currently underdiagnosed and undertreated in many European countries, leading to chronicity of symptoms and impairment, due to lack of, or ineffective treatment, and higher costs of illness.

Methods The European Network Adult ADHD and the Section for Neurodevelopmental Disorders Across the Lifespan (NDAL) of the European Psychiatric Association (EPA), aim to increase awareness and knowledge of adult ADHD in and outside Europe. This Updated European Consensus Statement aims to support clinicians with research evidence and clinical experience from 63 experts of European and other countries in which ADHD in adults is recognized and treated.

Results Besides reviewing the latest research on prevalence, persistence, genetics and neurobiology of ADHD, three major questions are addressed: (1) What is the clinical picture of ADHD in adults? (2) How should ADHD be properly diagnosed in adults? (3) How should adult ADHDbe effectively treated?

Conclusions ADHD often presents as a lifelong impairing condition. The stigma surrounding ADHD, mainly due to lack of knowledge, increases the suffering of patients. Education on the lifespan perspective, diagnostic assessment, and treatment of ADHD must increase for students of general and mental health, and for psychiatry professionals. Instruments for screening and diagnosis of ADHD in adults are available, as are effective evidence-based treatments for ADHD and its negative outcomes. More research is needed on gender differences, and in older adults with ADHD.

(c) 2018 The Author(s). Published by Elsevier Masson SAS. This is an open access article under the CC BYNC-ND license (http://creativecommons.org/licenses/by-nc-nd/4.0/).

\section{Introduction: the European Network Adult ADHD}

The European Network Adult ADHD (ENAA) was founded in 2003 to help improve the diagnosis and treatment of ADHD in adults in Europe and beyond. ENAA represents mental health care professionals and researchers from 28 countries with expertise on ADHD in adults (www.eunetworkadultadhd.com). The Section Neurodevelopmental Disorders Across the Lifespan (NDAL) of the European Psychiatric Association (EPA) joined our effort to

\footnotetext{
* Corresponding author at: European Network Adult ADHD, VUMc, Amsterdam, EPA, The Netherlands.

E-mail address: s.kooij@psyq.nl (J.J.S. Kooij).
}

provide this update of our first Consensus Statement on adult ADHD published in 2010 [1].

\subsection{Objectives of the updated consensus statement for clinicians}

Despite strong evidence on the clinical presentation, genetics, neurobiology, the burden of the disorder, and on safe and effective treatment for ADHD in adults, many people are still underdiagnosed and undertreated. Specialized clinical services remain scarce in most parts of the world, including Europe [2,3]. Our aim is to provide an update of the literature on assessment and treatment of adult ADHD to [1] increase awareness on ADHD as an impairing life-long neurodevelopmental condition up to old age [2]; update 
the assessment procedure for diagnosing ADHD in adults; and [3] give updated recommendations for appropriate treatments.

\subsection{Methodology}

Creating a Consensus Statement does not follow the same procedure as required for the development of a guideline, such as systematic reviews using formal ratings of the evidence. Most of the authors participated in the development of a first Consensus Statement on adult ADHD in 2010, and were asked to provide an update of the previous text based on new findings in the literature since the time of publication. Subgroups dealing with different subjects were formed. The subgroups reached consensus on the text among themselves before sending it to the first author. The first author put all paragraphs together and edited the text with the help of a few other coauthors (DW, SY, PA, DB). This draft of the manuscript was send to all authors for their comments. The first author checked the comments and implemented adjustments into the text, and send the final version to all authors for agreement. All authors agreed with the final version.

\section{Heritability and environment}

Family, twin and adoption studies from the last 20 years show that ADHD is a familial disorder with high heritability, indicating that a significant genetic component influences risk for the disorder [4-12]. Environmental factors such as severe institutional deprivation are also likely to play a role, either as main causal factors in a few cases [13] or by interaction with genetic risks. Family studies indicate a risk to first-degree relatives of 4-5 fold the population rate or higher, with prevalence rates around $20 \%$ among first degree relatives [14]. Data on ADHD in children and adolescents find average heritability of around 76\% [12]. Studies in adult twins using self-rated ADHD symptoms consistently report lower estimates of heritability, around 30-40\% [15-17]. One reason for lower heritability of adult self-reported ADHD symptoms may be from the use of self-ratings. These lead to lower estimates of heritability compared to informant ratings regardless of age, perhaps due to variable levels of awareness among individuals rating their own ADHD symptoms [18,19]. Studies combining data across informants [20], or using clinical diagnostic information [21] find heritability estimates for adult ADHD in the same range (70-80\%) as for children [22].

\subsection{Candidate genes}

Early molecular genetic studies of ADHD in children reported genetic associations with several candidate genes. Genetic variants within or near the D4 and D5 dopamine receptor genes provided the most consistent findings supported by meta-analysis [23]. Other specific candidate genes were implicated in the early studies $[12,24,25]$, but none have provided consistent evidence or been replicated in more recent large-scale genome wide association studies. Taken together the traditional neurotransmitter system genes appear to explain only a small amount of the variance in ADHD [26]. There is also some converging evidence for the role of genes that fit into a neurodevelopmental network involved in directed neurite outgrowth [27].

\subsection{Genome wide association studies (GWAS)}

More recent findings have emerged from genome-wide association studies [28]. The most recent dataset reported included over 20,000 ADHD cases and 35,000 controls. These data were used to estimate that around $30 \%$ of the heritability of ADHD is explained by common genetic variation. In total, twelve loci achieved genome-wide significance, including FOXP2; notable because prior work had implicated it in adult ADHD [29]. These findings place ADHD firmly on the path to detecting very large numbers of associated common genetic variants as more samples are accrued.

LD regression analyses that estimate genetic correlations between disorders find strong genetic links between ADHD and a range of outcomes including educational performance, depression, obesity, smoking and lung cancer [28]. A further finding is the very strong genetic correlation between the diagnosis of ADHD, and trait scores in general population samples, demonstrating that ADHD represent the extreme of a continuously distributed trait in the general population [30]. These finding confirm the polygenic nature of genetic liability to ADHD.

Rare copy number variants (CNVs) occurring on less than $1 \%$ of chromosomes are also known to play a role in a subset of individuals with ADHD [31,32]. CNVs were found to be 2-fold more common in children with ADHD within the normal IQ range, and 6-fold higher in those with IQs below 70 [32]. Specific genes suggested as CNVs linked to ADHD include the nicotinic alpha-7 acetylcholine receptor gene (e.g., [33]), several glutamate receptor genes [34] and neuropeptide-Y [35], although these findings remain inconsistent and hard to verify due to low frequency in the population.

\subsection{Molecular genetic studies of adult ADHD}

Molecular genetic studies of adult ADHD are less advanced, but are expected to confirm some genetic associations identified in childhood and find other genetic associations related to persistence or remission of ADHD in adult life [20]. A preliminary report at the International Neuropsychology meeting (Washington, 2018) found the genetic correlation between child and adult ADHD to be greater than $80 \%$. Most of the current research has been coordinated in Europe by Barbara Franke from the Netherlands for the International Multicentre Persistent ADHD Collaboration (IMPACT) group. This collaboration has successfully generated a multi-site sample of more than 3500 patients and continues to grow. To date several publications highlight potential associations with adult ADHD, some but not all of which are shared with genetic association findings in children [36-42].

\subsection{Environmental factors}

It has been known for a long time that environmental factors are associated with ADHD [43], particularly prenatal risk factors such as exposure to alcohol and drugs, valproic acid, high blood pressure, maternal stress during pregnancy, as well as preterm birth and low birth weight [44-46]. However sophisticated study designs are needed to clarify whether these association reflect direct effects of the environmental exposure or reflect genetically correlated risk measures. For example, although smoking during pregnancy is clearly associated with offspring ADHD, this association appears to be entirely accounted for by the genetic correlation between maternal smoking and offspring ADHD [47]. In contrast, evidence from Romanian adoptees suggests that severe early deprivation is causally related to ADHD in a dose dependent way [13]. Gene by environment interactions ( $\mathrm{G} \times \mathrm{E}$ ) have been proposed and may explain some of the missing heritability seen between heritability estimates derived from twin (0.76) and molecular genetic (0.22) data. However, to date no $G \times$ E effects have been clearly identified. The findings to date indicate that much more work is needed to understand the interplay between genetic and environmental risks. 


\section{Neurobiology of ADHD}

\subsection{Neuro-imaging: evidence for atypical gray and white matter areas}

Structural brain scans of adults with ADHD showed grey matter abnormalities in several brain areas, including the right frontal and prefrontal areas [48,49], anterior cingulate [50-52], the basal ganglia and the cerebellum [53-56] with some preliminary research also showing abnormalities of the visual cortex [57] Additionally, cortical thickness was found to be reduced in adult ADHD [56,58,59]. Some evidence suggests that grey matter abnormalities, in some subcortical regions, are more pronounced in children than adults. This might reflect the effects of age, medication, intrinsic heterogeneity of the ADHD syndrome, or a combination thereof [51,60-64].

Despite these reported findings the latest mega-analysis conducted by the Enigma consortium found no significant differences in brain structure between adult ADHD and controls; although, small but significant differences were found in children for subcortical regions including the accumbens, amygdala, caudate, hippocampus, putamen and intracranial volume with effects ranging from $d=.10-.15$ [65]. These findings indicate that while there are structural changes in subcortical brain regions in ADHD in children, these are relatively subtle effects that dissipate with increasing age.

Diffusion tensor imaging (DTI) highlighted that white matter tracts, including fronto-occipital, fronto-striatal, temporal and temporo-occipital fasciculi and part of the corpus callosum, bear microstructural abnormalities [66-71]. Additionally, some findings also linked microstructure variability to symptomatology such that greater inattention but not hyperactivity-impulsivity was associated with significantly lower fractional anisotropy (that is lower microstructural integrity) in the left uncinate and inferior fronto-occipital fasciculi compared to controls [70]. These results indicate that structural deficits in ADHD are not just confined to specific regions but involve interconnections among large scale brain networks $[68,71-73]$.

\subsection{Functional neuroimaging}

Regarding functional MRI (fMRI) studies, task-based and resting-state findings converge. Meta-analyses show that ADHD is associated with dysfunctions in several domain-specific frontostriatal and fronto-cerebellar neural networks. Thus a metaanalysis of 39 child and 16 adult ADHD fMRI studies concluded that in ADHD there are significant dysfunctions in multiple neuronal systems involved in higher-level cognitive functions [74]. These include hypoactivations in the frontoparietal executive control network, putamen, and ventral attention network, which is consistent with the classical model of ADHD as a disorder of deficient fronto-striatal activation.

Hyperactivations are also seen in regions of the default mode and visual networks, which support the contemporary view that ADHD is associated with faulty regulation of relationships between default mode and task positive networks. Similar findings come from meta-analyses, which show consistent underactivation in inferior fronto-striatal networks during cognitive tasks [75], in dorsolateral fronto-striato-parietal networks during attention tasks [75], and in fronto-cerebellar networks for timing functions [76]; in addition to abnormally enhanced activation in default mode regions [76].

The recent focus on resting state fMRI (RS-fMRI) identified multiple intrinsic neural circuits, reflecting functional connectivity within and between regions which is continuously encoded in the spontaneous activity of the brain [77]. The intrinsic fronto-parietal, dorsal attentional, visual, motor and default mode networks all overlap with regions showing differential task activations during inhibition, attention, or working memory tasks in ADHD compared to controls [78]. Despite the wealth of established findings from fMRI and RS-fMRI studies of ADHD, cross-sectional neuroimaging data is correlational in nature and causal inferences cannot yet be made.

More recently outcome studies of children diagnosed with ADHD has been able to compare functional brain change in adults with persistent and remitted ADHD and compare these to agematched controls. The largest such follow-up study to date, of 205 children with ADHD, found that persistence of ADHD was associated with loss of the balance of connections within the default mode network, and connections between the default mode and those supporting attention and cognitive control. In contrast there were no differences in these networks between those whose ADHD had remitted and non-ADHD controls [79].

Overall, despite the wealth of established findings from fMRI and RS-fMRI studies of ADHD, cross-sectional neuroimaging data is correlational in nature and causal inferences cannot yet be made. The finding that certain functional brain changes are seen to differ between persistent compared to remitted cases of childhood ADHD sheds some light on likely causal processes, but further longitudinal data is still required before firm conclusions can be drawn.

\subsection{Neuropsychological and electrophysiological tests}

As a group, individuals with ADHD are characterized by altered neuropsychological functioning across a variety of executive function (EF) measures. However, thus far there is neither a neurobiological nor a neuropsychological test (battery) for ADHD with sufficient positive predictive power to establish the diagnosis at the individual level [80]. In one study, the vast majority of neuropsychological instruments showed poor discriminative ability compared to clinical assessment measures such as the ASRS Screener v1.1 and the DIVA 2.0 Diagnostic Interview for ADHD in adults, with an overall classification accuracy ranging from $53 \%$ to $66 \%$ [81]. Nevertheless, when used in combination with the DIVA 2.0, objective cognitive performance tests measuring omission and commission errors, and physical activity, were found to increase the correct classification of adult ADHD [81]. There is currently insufficient evidence to warrant the use of neuropsychological testing to determine the diagnosis of ADHD [82] or to predict impairment in major life domains [83].

Moreover, clinicians should also be aware of the possibility that a few individuals may feign ADHD symptoms to gain external incentives, like stimulant medication or special academic accommodations. There is some evidence supporting the effectiveness of performance validity tests (PVTs) in differentiating between genuine and feigned ADHD compared to rating scales [84].

Electrophysiological studies suggest that brain dysfunctions are involved in the central components of ADHD in both children and adults [85-89], although the finding of increased DAT density remains controversial [90,91].

Data from Electro Encephalography (EEG) is relatively scarce in adult ADHD. Generally, EEG studies of ADHD find similar deficits in adults and children, while some findings change with age and might be sensitive to developmental changes [92]. Despite US Food and Drug Administration approval of an EEG device (2013) that assists in the diagnosis of ADHD subtypes [93-95], this remains controversial [96]. EEG tests are not sufficiently accurate but could be useful to increase diagnostic certainty.

\section{ICD and DSM criteria for ADHD}

There are two diagnostic manuals used to diagnose ADHD: The Diagnostic and Statistical Manual of Mental Disorders (DSM) and 
the International Statistical Classification of Diseases and Related Health Problems (ICD). As ADHD has been recognized as a disorder affecting individuals across the lifespan, the diagnostic criteria for adolescents and adults have been adjusted in the DSM-5, published in May 2013:

1) ADHD is now in the chapter Neurodevelopmental Disorders, which includes conditions associated with factors affecting the brain development.

2) Diagnostic criteria have been adapted by adding some examples describing how ADHD symptoms are expressed across the lifespan.

3) The age of onset criteria has been changed requiring several symptoms to be present before age of 12 years, instead of some symptoms and impairment by age 7 .

4) The term "subtype" has been replaced by "presentation", reflecting the variation of ADHD symptoms within the same individual during the lifespan.

5 ) The symptom threshold required has been reduced to 5 symptoms instead of six for older adolescents and adults ( $>17$ years) in either the inattention or hyperactive/impulsive domain.

6) Criteria requiring significant impairment has been modified to "clear evidence that symptoms interfere with or reduce the quality of social, academic and occupational functioning", with specifiers regarding severity level.

7) The presence of Autism Spectrum Disorder (ASD) is no longer an exclusion criterion, consistent with evidence showing their frequent co-occurrence.

8) ADHD Not Otherwise Specified (NOS) has been changed into Other Specified ADHD and Unspecified ADHD.

The revision of ICD-10, ICD-11 has been published in June 2018. ICD-11, developed by the World Health Organization now refers to ADHD as Attention Deficit Hyperactivity Disorder, instead of previously Hyperkinetic Disorder (HKD) [97]. It now uses similar requirements as the DSM-5 regarding age of onset, and the same 3 presentation types. In Europe, ICD codes are often used for statistics on mortality, morbidity and by insurance agencies for health-related reimbursements [98], whereas DSM is primarily used in clinical practice by licensed mental health care professionals [99].

The diagnostic assessment starts by evaluation of self-reported symptomatology. The clinical interview is essential for diagnosing ADHD in adults, which investigates the characteristic symptoms and impairments of ADHD in both childhood and adulthood. In children and adolescents, informants' ratings are higher correlated with heritability and cognitive and EEG findings than self-ratings [19]. Also prevalence and persistence rates increase when parent reports are used [19]. In adults this may be slightly different, as some research shows that the adult patient is the best informant [100]. The presence of a family member however (a parent and/or the partner) during the assessment can still provide valuable additional information, e.g. on severity and its translation into daily activities.

There is compelling evidence that a cut-off of four current symptoms is the most appropriate for an adult diagnosis [101,102]. However, due to concern about the possibility of an artificial increase in the prevalence of the disorder, DSM-5 lowered the threshold for diagnosing ADHD from six to five symptoms for those older than 17 years of age. Several items have been expanded by some illustrative examples to facilitate the recognition of the disorder throughout development. Although not included in thecriteria as such, behaviors reflecting executive dysfunction usually appear clearly during the assessment, when patients describe problems with organization, facing daily responsibilities, solving problems, managing time and self-regulating (inhibiting) behaviors.

DSM-5 also highlights the importance of mood lability and emotional dysregulation as "an associated feature that support the diagnosis". Although emotional dysregulation may dominate the clinical presentation [103-105], it is not a criterion for classifying individuals as it lacks specificity, occurring in many other mental health conditions.

DSM-IV required that symptoms and impairment were present before age 7 , but as research demonstrated no differences between children with an age of onset before and after age 7 [106] this criterion was changed to several symptoms by age 12 . Similar findings have also been reported regarding adults reporting lateronset of symptoms [107,108], and there is disagreement both within and across sources concerning recall of symptom onset [109]. The fact that adults with ADHD frequently fail to recall childhood behavior led to the suggestion that clinicians take note that the onset of the disorder was during the developmental period, or they should use age 16 years as the upper age limit. Using this criteria captured all cases of childhood ADHD and 99\% of adults with the disorder [110]. The decision of DSM-5 to extend the age of onset to 12 instead of 16 may have a negative impact on adults with ADHD who have difficulties with retrospective recall of childhood behaviors, and may not receive the diagnosis for this reason. This may be particularly true for those who had some compensation due to high intelligence, or lived in a highly structured or supported environment, or presented predominantly with inattentive symptoms. In such cases, the presence of a collateral informant (generally a parent or spouse) is of great value. Many adults with ADHD that are used to their lifelong symptoms, have limited awareness of how ADHD symptoms adversely impact their interpersonal relationships and affect their life; some reporting higher symptoms but lower impairments or vice versa.

Such inconsistency has been attributed to a lack of introspection and an incoherent self-view [111,112], and supports the utility of a collateral informant. If a significant other is not available, school reports or social care reports may be helpful.

\subsection{Clinical picture}

\subsubsection{Inattention and hyperfocus}

Patients with mainly inattention problems are often slow to think and formulate due to distractions. They may formulate things in a long-winded and tangential way, losing themselves in irrelevant details and having difficulty making decisions. A difficulty for the clinician is that this may hinder the diagnostic assessment. Patients may also over-concentrate or 'hyperfocus'. This phenomenon most commonly occurs when engaged in activities that the patient finds very interesting and/or provide instant gratification, such as computer games or online chatting. For such activities, concentration may last for hours on end, in a very focused manner.

\subsubsection{Hyperactivity}

With respect to hyperactivity, adults do not present in the same way as children. Their hyperactivity usually manifests in a more subtle way. Clinicians need to assess their feelings of restlessness. A first impression of mobility is not definitive; sitting calmly during the diagnostic assessment does not exclude any ADHD. Hyperactivity in adults often manifests itself as feelings of continuous inner restlessness or agitation, talking too much, ceaseless mental activity, not being able to relax properly or needing alcohol or drugs to relax and/or sleep. Hyperactivity and/or restlessness may be temporarily relieved by the patient engaging in excessive sport activities, and in such cases the person may suffer physical 
ailments as the body may have insufficient time to recover and/or due to sustained injuries.

\subsubsection{Impulsivity}

Impulsive behavior and associated interpersonal conflicts often have consequences for relationships with family, friends, colleagues and employers. It may also seriously impact on personal finance when impulsive spending causes debt. Impulsive binge behaviors may also be present (e.g. binge eating), often to combat restlessness or due to a need for immediate gratification. Closely related to impulsivity are 'sensation seeking' behaviors when patients may seek out excitement from novel and thrilling stimuli. These often involve risk taking behaviors such as playing with fire, reckless driving, sexual risks, and provocative behavior leading to fights.

\subsubsection{Emotional dysregulation}

Emotional dysregulation is listed by DSM-5 as a characteristic feature of ADHD, supporting the diagnosis [113]. The type of emotional dysregulation seen in ADHD has been characterized as deficient self-regulation of emotional symptoms such as irritability, frustration and anger [114], and low frustration tolerance, temper outbursts, emotional impulsivity, and mood lability [115]. Emotional dysregulation in ADHD is different from episodic symptoms such as marked sustained irritability occurring within the context of altered mood states, such as an episode of depression or mania. In ADHD, emotional symptoms tend to reflect short lived exaggerated changes, often in response to daily events, with rapid return to baseline within a few hours [114]. Whether the type of emotional instability seen in ADHD is qualitatively different to that seen in other chronic conditions such as borderline personality disorder or post-traumatic stress remains unclear.

\subsubsection{Excessive mind wandering}

Another common feature of adult ADHD is excessive mind wandering, also referred to as mental restlessness [116-118]. In DSM-5 mind wandering is briefly mentioned as the occurrence of unrelated thoughts. Although mind wandering is a universal experience, some forms of mind wandering are detrimental because they interfere with task performance. Adults with ADHD frequently report a distractible mental state with multiple unrelated thoughts that are constantly on the go and jump from one topic to another $[119,120]$. Mind wandering is also a feature of other mental health disorders such as depressive or obsessive disorders. However, in ADHD mind wandering is characterized by unfocused, short lived distractible thoughts with no pattern of repeated thoughts or abnormality of content. Research found that excessive mind wandering was strongly correlated with ADHD symptoms, was a strong predictor of the diagnosis (sensitivity and specificity around $90 \%$ for case-control differences), co-varied with ADHD symptoms over a 6-month period, and was a better predictor of ADHD-related impairments than the inattentive and hyperactive-impulsive symptoms of ADHD [120]. In ADHD it can be measured using the Mind Excessively Wandering Scale $[116,118,120]$ (Table 1 ).

\subsubsection{Behavioral self-regulation (executive function deficits)}

ADHD has been described as a disorder of executive functions such as inhibition and working memory. These include problems organizing, prioritizing and initiating work; focusing, sustaining and shifting attention to tasks; regulating alertness, sustaining effort and processing speed; managing frustration and regulating emotions; utilizing working memory and accessing recall; and monitoring and self-regulation of behavior [121,122]. Although clinically these are good descriptions of the types of difficulties experienced by adults with ADHD, behavioral measures do not
Table 1

Examples of ADHD-related symptoms.

\begin{tabular}{|c|c|}
\hline Inattention & $\begin{array}{l}\text { - Forgetfulness } \\
\text { - Distractibility } \\
\text { - Chaotic presentation } \\
\text { - Difficulty organizing \& planning } \\
\text { - Difficulty listening } \\
\text { - Difficulty with punctuality (arriving either too late or too } \\
\text { early) } \\
\text { - Temporary hyperfocus for highly salient tasks, but no } \\
\text { control of attention when required or for many essential } \\
\text { activities of daily life } \\
\text { - Getting lost in details } \\
\text { - Doubtfulness - unable to make decisions or solve } \\
\text { problems } \\
\text { - Needing too much time to complete tasks } \\
\text { - Mifficulty starting and finishing tasks } \\
\text { Mind Wandering: } \\
\text { - Unrelated spontaneous thoughts, constantly on the go, } \\
\text { jumping and flitting, multiple thoughts at the same } \\
\text { time } \\
\text { - Associative thinking }\end{array}$ \\
\hline Hyperactivity & $\begin{array}{l}\text { - (Inner) Restlessness } \\
\text { - Difficulty relaxing } \\
\text { - Pacing up and down } \\
\text { - Talking too much and too loud } \\
\text { - Fidgeting, rocking or tapping } \\
\text { - Not being able to bear an office job because of } \\
\text { restlessness } \\
\text { - Knocking things over because of excessive mobility } \\
\text { - Being able to sit still but this comes with muscle strain } \\
\text { - Restless sleep }\end{array}$ \\
\hline Impulsivity & $\begin{array}{l}\text { - Acting without thinking } \\
\text { - Difficulty waiting turn - linked to feelings of irritability } \\
\text { - Blurting things out that cause distress to others } \\
\text { - Interrupting others } \\
\text { - Impatience and difficulty waiting turn } \\
\text { - Spending too much } \\
\text { - Walking out of jobs } \\
\text { - Starting relationships quickly } \\
\text { - Not being able to postpone gratification } \\
\text { - Sensation seeking and risk taking behaviors } \\
\text { - Binge eating }\end{array}$ \\
\hline $\begin{array}{l}\text { Emotional } \\
\text { dysregulation }\end{array}$ & $\begin{array}{l}\text { - Mood lability } \\
\text { - Low frustration tolerance } \\
\text { - Emotional impulsivity } \\
\text { - Irritability } \\
\text { - Anger outbursts } \\
\text { - Premenstrual increase of symptoms }\end{array}$ \\
\hline
\end{tabular}

correlate well with cognitive or neuropsychological tests of executive control [121-123]. A distinction needs to be made between rating scale measures of behaviours reflecting selfregulation of behavior referred to as EF (behavioral) deficits, and the results of neurocognitive tests of EFs such as working memory and inhibition. Neuropsychological test scores reflecting executive functioning lack ecological validity in that they have no significant relationship to behavioural rating scale measures of EF [124]. The EF test scores also are very poor at predicting impairment in a variety of domains of major life activities, compared to $\mathrm{EF}$ behavioural rating scales [125].

\subsubsection{Burden of $A D H D$}

The impairments associated with ADHD across the lifespan are impressive. ADHD is associated with learning difficulties, school dropout, underachievement at work [126], frequent job changes [127], chronic fatigue [128], financial problems, gambling and 
internet use [129,130], home and traffic accidents leading to increased mortality rates [131-133], relationship difficulties and intimate partner violence [134,135], early onset of addiction [136], teenage pregnancies and sexual transmitted diseases [137,138], a two-fold increased smoking rate [139], an increased number of suicide attempts and self-harm in adolescents [140,141], and increased criminality [142,143]. Moreover, physical disorders and ailments may become chronic due to forgetfulness, health problems induced by a negative lifestyle, poor eating and sleeping habits, and lack of health care follow-up [144-147]. ADHD has further been associated with auto-immune diseases [148], obesity [149], and physical multi-morbidity. In one large study, individuals with more than 4 diseases had over more than 3-fold higher odds of possible ADHD [146]. The risk of diabetes, hypertension, cardiovascular disease and cancer, that are related to obesity, may be increased as well. An additional burden on family life may be the presence of one or more children with ADHD, which happens frequently due to the high familial risks of the disorder.

Clinicians should also be aware that high functioning adults with ADHD may not present with a typical pattern of functional impairments in their daily life. Adaptive or compensatory skills can develop that mask the more overt behavioral problems related to ADHD [150]. Some may find work that is well suited to their symptom profile. Furthermore, in ADHD neurocognitive performance and inattentive symptoms are sensitive to the salience of task activities [151,152]. Such people with ADHD may excel in certain aspects of their lives, but still be impaired in others, such as more routine and mundane tasks such as paying bills, looking after the house, or developing stable social relationships. Problems can include subjective distress from symptoms such as mental and physical restlessness, sleep problems, and emotional instability; and the use of drugs such as cannabis or alcohol to reduce these symptoms.

\section{Prevalence of ADHD across the lifespan}

In childhood, ADHD is among the most common psychiatric disorders with a prevalence rate of 3-5\% [153]. For this age group, well established diagnostic and treatment services are available throughout most of Europe. In the last four decades, a large body of evidence has accumulated, showing how in the majority of cases ADHD is a lifespan disorder, persisting as either the full blown disorder, or in 'partial remission' with persistence of some symptoms and continued clinical and psychosocial impairments [154-161]. The prevalence of ADHD in adults across twenty countries was recently estimated at $2.8 \%$, with a range between 1.4 - 3.6\% [3]. ADHD was also found in a Dutch population study to persist into old age ( $>60$ years) with a prevalence of $2.8-4.2 \%$ depending on cut-off ( 6 or 4 current symptoms respectively), and associated with impairment [162-166]. ADHD in older adults is accompanied by increased rates of mood and anxiety symptoms, general health problems, conflicts, divorce, loneliness, and a lower income, showing a similar pattern of problems as in younger age groups. Research exploring the needs for treatment of older adults with ADHD has commenced, and the first treatment protocol of older adults with ADHD has been published [167].

\subsection{Sex issues}

Sex differences in ADHD diagnosis are well documented, with girls being less likely to be diagnosed, and sex ratios ranging between $1: 5$ to $1: 9$ [168]. Such discrepancy is less evident in epidemiological research in children where the sex ratio is $1: 3$, suggesting under recognition of ADHD in girls in the clinic. In both epidemiological and clinical studies of adult ADHD the sex ratio is closer to 1:1 [169]. Several factors may explain the sex disparity during the lifespan. Girls with ADHD may have less hyperactive/impulsive symptoms than boys; because of higher disruptiveness, boys are more likely to be referred by parents and teachers, whereas girls remain undiagnosed [170]. Missed diagnosis may be due to a lack of knowledge and recognition of ADHD in girls by health care professionals, and to the presence of other conditions: low self-esteem, anxiety as well affective disorders occur frequently in females with ADHD, and it is possible that ADHD symptoms may be mistakenly attributed to such comorbidities [171,172]. Females with ADHD appear to develop better coping strategies than males, and are better able to mask symptoms of ADHD throughout childhood. However, this may no longer work well when they face salient life challenges, such as leaving school, attending college or university, commencing employment, managing intimate relationships, and taking responsibility for their own life decisions [173]. Different genetic liability between the sexes [174], as well neuroendocrine factors affecting the dopaminergic system, such as thyroid and estrogen hormones [172,175], have all been also suggested to play a role in the masking of ADHD in girls and women. In addition, girls and women with ADHD are less well studied than males.

Women with ADHD are particularly vulnerable to early adversities, health and mental health problems compared to controls [176]. A higher prevalence of insomnia, chronic pain, suicidal ideation, generalized anxiety disorder, depressive disorders, a greater vulnerability to nicotine dependence [176,177] and an increased likelihood of risky sexual behaviors [138] has been reported in women with ADHD in comparison with controls.

\subsection{Transition of adolescents to adult mental health services}

As two-thirds or more of children with ADHD continue to have impairment into adulthood [178], many require the transition from child to adult mental health services. However, transition between services is generally difficult, placing youths with ADHD in an even more vulnerable position [179]. Research shows that disruption of care during transition adversely affects clinical outcome [180,181]. Clear recommendations have been formulated, mostly based on clinical experience, to facilitate successful transition of patients with ADHD from child to adult mental health services [1,182-185]. These are a) transition should ideally be completed by the age of 18 years, $b$ ) transition should be planned in advance by both child and adult mental health services, $c$ ) young people with ADHD and their parents should have sufficient information regarding the transition process (e.g. psychoeducational material including available services), d) both continued parental care and child's growing autonomy should be considered, e) if necessary a formal meeting involving child and adult mental health services (with specific knowledge on this age group) and patients and parents should be considered. All these can help to prevent the drop-out of young people with ADHD from services. However, the reality is quite different, as indicated by two reviews [186,187]. Compared to other diagnostic groups, youth with ADHD were significantly less likely to be referred, they were more likely to refuse referral, and a significant number remained in child services well beyond their $18^{\text {th }}$ year. Studies also have found transition policy deficits [186,188], suboptimal experience of transition when it does occur [186,189], a dearth of adult ADHD services [190], and a lack of expertise on ADHD amongst adult clinicians [3,191]. This suggests there is an urgent need for a multifaceted approach combining transition specific clinical guidelines, and funding for the training the training of clinicians, to ensure that those in need of ongoing intervention may successfully transition to adult services.

\subsection{Late-onset $A D H D$ ?}

Recent longitudinal studies have indicated that besides typical childhood onset ADHD, with the full diagnostic criteria being met 
before the age of 12 years, there may be later-onset cases with onset of the full diagnostic criteria beyond this age [104,189,190]. These findings have proven controversial due to severe methodological limitations [192,193], however the large majority of later onset cases appear to meet the DSM-5 age of onset criteria of several symptoms by the age of 12 [113]. Late onset of symptoms was evaluated in the control arm of the long-term follow-up of the Multimodal Treatment study of ADHD (MTA). In most cases, other factors were present that could discount the late onset of ADHD symptoms and exclude the diagnosis of ADHD [194], such as symptoms representing nonimpairing cognitive fluctuations, a comorbid disorder, or the cognitive effects of substance use [192]. However, there remained a very small sample of adolescent onset cases. Another population cohort study found that the majority of those with apparent late-onset ADHD had high ADHD scores at least one point in childhood, suggesting that they may have been misclassified on the basis of their score at age 12 years [195]. These cases with high score before the age of 12 years might not have met full criteria before the age of 12 years, but would meet the current DSM-5 criteria for several symptoms in childhood. One conclusion is that clinicians should be aware that subthreshold cases of ADHD during childhood might go on to meet the full diagnostic criteria as older adolescents. Clinicians should take care to fully assess impairment, psychiatric history, and substance use when diagnosing and treating cases with apparent later-onset ADHD [192].

\section{Screening and diagnostic assessment}

\subsection{Screening}

Several screening tools are available for ADHD in adults. The validated tool recognized by the World Health Organization (WHO) and updated for DSM-5 criteria is the Adult ADHD Self report Rating Scale (ASRS). This revised ASRS was studied in managed care, the general population and in a clinical group. The sensitivity was 91.4\%; specificity 96.0\%; AUC, 0.94; PPV, 67.3\% [196]. The previous version of the ASRS has been translated into many languages (see http://www.hcp.med.harvard.edu/ncs/asrs.php). The Wender Utah Rating Scale assesses besides ADHD a broader spectrum of symptoms that often accompany ADHD or are comorbid. Several other scales that ask about the 18 items as defined in the DSM-5 to classify ADHD are available, see Table 2.

A key question is who should be screened for ADHD. In general, since the hallmark of adult ADHD is a chronic trait-like condition that emerges out of childhood or early adolescence, anyone presenting with such a clinical picture should be screened [2]. This should include those with chronic histories of inattentive, restless or impulsive behaviors, as well as those with emotional instability. Targeted groups where rates of ADHD are significantly increased and should therefore be screened include family members of people with ADHD, and those with a history of behavioral problems, any chronic mental health disorder including anxiety, depression, cyclothymia, personality disorder, bipolar disorder, substance use disorders, those with multiple physical diseases [146], and those within the criminal justice system [197].

\subsection{Diagnostic assessment}

For diagnostic assessment, the use of a semi-structured diagnostic interview is advised, such as the Diagnostic Interview for ADHD in adults, second edition (DIVA 2.0) [198], based on the DSM-IV-TR criteria. DIVA 2.0 is available online without charge, currently in 19 languages (www.divacenter.eu). The Conner's Adult ADHD Diagnostic Interview for DSM-IV (CAADID) has been validated in English and Spanish [199]. DIVA 2.0 has been validated in two European populations [81,199], and is increasingly used in international research. A DIVA 2.0 app is available in the App and Google Play stores. The update of DIVA 2.0 for DSM-5 criteria into 'DIVA-5' in all languages is ongoing. DIVA-5-ID, for people with Intellectual Disability (ID) and Young DIVA, for children and adolescents, are new versions of DIVA-5. An alternative is ACE+ (http://www.psychology-services.uk.com/resources.htm), a semistructured diagnostic interview to assess ADHD in adults $(>16$ years). ACE + assesses the core symptoms of ADHD in both adulthood and childhood, the extent to which they impair functioning, and the presence of co-existing conditions. ACE + is currently online available in 7 languages, with more translations underway. For these and other diagnostic tools, see Table 2.

\subsection{The assessment process of $A D H D$ and comorbidity}

Diagnosis of ADHD is based on a careful and systematic assessment of a lifetime history of symptoms and impairment. Central to this process is the assessment of childhood-onset and current symptoms of ADHD, and the presence of symptoms and impairment in at least two domains (school, work, home, interpersonal contacts). For this lifetime assessment, collateral information from family members and spouse are useful. It is important to take a full medical history of psychiatric and somatic conditions, as well as a family history of psychiatric and neurological problems. High intelligence should be taken into account as a potential moderator in the diagnostic assessment, as ADHD is underdiagnosed in patients with high intelligence because they use more compensatory strategies [200]. Clinicians should also be aware that high functioning adults with ADHD may not present with a typical pattern of functional impairments in their daily life. Adaptive or compensatory skills can develop that mask the more overt behavioral problems related to ADHD [150]. Some may find work that is well suited to their symptom profile. Furthermore, in ADHD neurocognitive performance and inattentive symptoms are sensitive to the salience of task activities [151,152]. Such people with ADHD may excel in certain aspects of their lives, but still be impaired in others, such as more routine and mundane tasks such as paying bills, looking after the house, or developing stable social relationships. Problems can include

Table 2

Open access Scales and Interviews for Diagnostic Assessment of ADHD in adulthood.

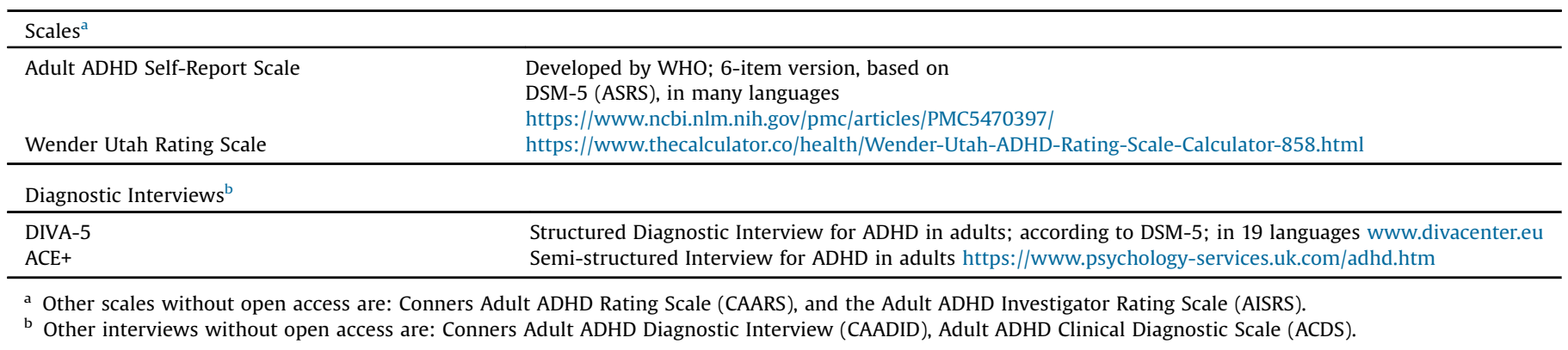


subjective distress from symptoms such as mental and physical restlessness, sleep problems, and emotional instability; and the use of drugs such as cannabis or alcohol to reduce these symptoms.

Adult diagnoses may be missed in clinical practice due to lack of knowledge about ADHD in adulthood among practitioners and due to the high frequency of comorbid psychiatric conditions [201]. The lifetime co-morbidity rate is $60-80 \%$. Having three or more disorders was associated with a ten-fold increase of the chance of having ADHD in a population study in 20 countries [3]. Before treatment start, all comorbidities must be established so that the best order of treatment can be determined together with the patient. In the study by Fayyad et al, data on ADHD and comorbidities was collected on 26,744 respondents [202]. In adults with ADHD having one comorbidity was found in $23 \%$ of cases, two in $14 \%$ of cases and three in $14 \%$ of cases. Rates were particulary high for any mood disorder (22\%), any anxiety disorder (34\%), substance use disorders (11\%) and any behavioural disorder (15\%).

Psychiatric comorbidity is thus a clinically important dimension of ADHD heterogeneity and a factor that contributes to the persistence of ADHD in adulthood [203,204]. It is important for the diagnosis of ADHD, as well as the correct targeting of treatments, to identify mood, anxiety, eating, sleep, somatic and substance use disorders, in addition to personality, tic and autistic spectrum disorders [205]. Because adults with ADHD often exhibit low selfesteem, low mood, mood lability and irritability, these symptoms may sometimes be confused with dysthymia, cyclothymia, bipolar disorder or borderline personality disorder. Furthermore, daily mood changes in ADHD are very common, and represent a poorly regulated but essentially normal range of moods, rather than the more severe extremes of depression and elation as seen in bipolar disorder. It has been argued that chronic mood instability should be considered part of the core syndrome of ADHD [206,207]. ADHD and borderline personality disorder share symptoms of impulsivity, mood instability, anger outbursts and feelings of boredom $[158,208,209]$. In the ADHD patient, impulsivity and anger are usually short-lived and thoughtless rather than driven. Conflicts in relationships, suicidal preoccupation, self-mutilation, identity disturbances and feelings of abandonment are usually less intense than in borderline personality disorder. However, the differences may not be clear-cut because these symptoms are chronic and trait-like in both conditions [210].

ADHD in children is also associated with increased rates of neurodevelopmental disorders like autism spectrum disorder, dyslexia and impaired motor coordination which are thought to arise from overlapping genetic influences [211]. Such neurodevelopmental comorbidities are less well studied in adults, but they are commonly observed in clinical practice and may lead to continued impairments. As the order of treatment will depend on the presence and severity of comorbidities, evaluation of comorbid disorders is a key component of the ADHD assessment process, using appropriate clinical diagnostic approaches.

\section{4. $A D H D$ and criminality}

The prevalence of ADHD is increased in forensic populations compared to the general population [212], and the risk of criminality is increased in individuals with ADHD, especially in those with comorbid oppositional defiant disorder, conduct disorder, substance misuse and antisocial personality disorder [213]. A meta-analysis comprising 42 studies from 15 countries reported a 5-fold increased prevalence of ADHD in youth prison populations (30\%) and a 10-fold increased prevalence in adult prison populations (26\%) as compared to the general population [214]. When using diagnostic clinical interviews, the estimated ADHD prevalence in prisoners was $25.5 \%$, without significant differences for gender and age [214]. Further, inmates with ADHD compared to those without are reported to have higher rates of psychiatric morbidity including substance misuse, an earlier onset of offending, more violent offences, criminal recidivism and more frequent and severe institutional aggression [215,216].

\section{Treatment}

\subsection{Effective treatments}

The treatment of adults with ADHD should follow a multimodal and multidisciplinary approach, which includes psychoeducation, pharmacotherapy, cognitive behavior therapy (CBT) and coaching for ADHD, which are all discussed in this article.

Ideally, the treatment plan also involves the adult's partner, family or close relationships, and in some cases systemic (family) therapy may be required when gross disruption to family relationships and functioning is present.

\subsection{Treatment focus in comorbid ADHD}

In the most recent report of 20 nationally or regionally representative World Mental Health surveys, data on ADHD and comorbidities was collected on 26,744 respondents [202]. In adults with ADHD having one comorbidity was found in $23 \%$ of cases, two in $14 \%$ of case and three in $14 \%$ of cases. Rates were particulary high for any mood disorder (22\%), any anxiety disorder (34\%), substance use disorders (11\%) and any behavioural disorder (15\%). Treatment of ADHD is therefore most often in the context of co-occuring disorders.

Before treatment starts, all comorbidities must be established so that the best order of treatment can be determined together with the patient. In general, the most severe disorder is prioritized. For instance, psychosis, bipolar disorder, substance abuse, severe depression and severe anxiety are usually treated first. Milder mood or anxiety disorders, and emotional instability, may respond to treatment of ADHD and can be treated at the same time as ADHD. Drug and alcohol abuse should be stabilized but can be treated at the same time as ADHD.

\subsection{Psychoeducation on ADHD}

According to consensus based on good clinical practice and the need to work on an informed consent basis within a multimodal treatment approach, psychoeducation should be the first step as a standard of care [217]. First evidence from an open trial and a randomized clinical trial shows, that patients and significant others who attend a structured psychoeducation program increase their knowledge about ADHD, and improve the quality of their relationships and psychological well-being [218,219].

\subsection{Pharmacotherapy for $A D H D$}

\subsubsection{Introduction on pharmacotherapy}

In the first European Consensus Statement [1] psychostimulants (methylphenidate and dexamphetamine) were recommended as the first-line pharmacotherapy for adult ADHD $[1,184,220]$, as they exert moderate-to-high clinical effects, with average effects higher than atomoxetine (ATX) and other nonstimulant medications [2]. There were, however, no head-to-head studies providing robust comparative analysis of efficacy differences [221]. Across most of Europe, lisdexamfetamine (LDX) has been introduced as a slow release formulation of dexamphetamine. The recent systematic review and network meta-analysis on the comparative efficacy and tolerability of medications for ADHD in children, adolescents and adults by Sam Cortese et al. 
showed, that the first pharmacological choice for ADHD in children and adolescents is methylphenidate, and amphetamines in adults [222]. In fact in adults, amphetamines were not only the most efficacious compounds, as rated by clinicians and by self-report, but also as well tolerated as methylphenidate and the only compounds with better acceptability than placebo.

\subsubsection{Licensing}

Licensing of ADHD medications for adults is more diverse than in 2009 [1], reflecting greater understanding of ADHD, and efforts to market ADHD medications in Europe. In Denmark, Ireland, Norway, Sweden, Switzerland, the Netherlands and the United Kingdom, most ADHD medications can be prescribed, either with a full license (e.g. Medikinet $\AA$, Strattera $\AA$, Elvanse $®$ ) or transitional licenses (e.g. Concerta XL $®$ ) and off-label prescribing is endorsed by national guidelines and formularies. Dexmethylphenidate (Focalin XR®) is licensed in Switzerland only. In other countries, only a limited selection of medications is available for funding by the state sector, but off label prescribing is possible. In another group of countries (e.g. Greece, Slovenia, Poland), only very few ADHD medications are available, with off-label prescribing mostly in the private sector. The European Network on Adult ADHD (ENAA) and the Neurodevelopmental Disorders Across the Lifespan (NDAL) section at EPA strongly recommend that evidence-based treatments for adult ADHD are made more available and licensed across European countries.

\subsubsection{Efficacy and adverse effects of stimulants}

Meta-analyses of randomized controlled trials (RCTs) demonstrate the efficacy of stimulants and ATX in the reduction of ADHD symptoms in adults [223-227]. Standardized mean differences (SMDs) range from 0.4 to 0.7 , with stimulants showing greater efficacy than ATX [224]. The longest RCT in adults still found significant effects of MPH after one year [228]. National registry data also suggest long term benefits. Although these studies are not definitive due to lack of randomization and controls, they demonstrate 'real-world' societal benefits associated with the use of ADHD medications. These studies show that during periods of receiving medications for ADHD there are marked reductions in transport accidents and mortality rates [132,229], criminal convictions [230], suicidal behavior [231], violent reoffending [230], depression [232] and substance misuse [233]. Similar analyses with antidepressants find no effects, suggesting the effects are specific to ADHD medications.

A 2011 meta-analysis [225] revealed that MPH (mean dose $41.2-82 \mathrm{mg} /$ day) exerted a moderate effect on ADHD symptoms, with large effects observed at doses of $>77.4 \mathrm{mg} /$ day. Immediate release (IR) MPH has a short duration of action of maximum $4 \mathrm{~h}$. Due to difficulties with compliance when needing to take medication up to several times a day, long-acting MPH preparations have been developed, with durations of action ranging between $6-12 \mathrm{~h}$.

The recommended dose range of Immediate Release dexamphetamine (IR) is 5-60 mg/day [220]. Lisdexamfetamine (LDX) has a slow release profile giving the drug a relatively low abuse profile [234]. LDX is taken once daily with a mode of action of up to $14 \mathrm{~h}$ [235]. Three RCTs in adults indicate moderate to large effects on ADHD symptoms [236-238] (SMD = 0.97) [239], comparable to MPH. The safety and tolerability profile is similar to other stimulants [240,241].

The main adverse effects of stimulants are increased heart rate and blood pressure, and reduced appetite and sleep [242-245]. Heart rate, blood pressure, sleep problems and weight are therefore assessed before, and monitored at least twice a year during treatment. Serious cardiac complications are rare [243,246,247] with reported risks for myocardial infarction, sudden cardiac death, ventricular arrhythmias or stroke no more than $0.2-0.4 \%$ higher in one study [248]. MPH might trigger arrhythmias in patients with congenital heart diseases [249]. The consensus is caution in patients with known cardiac defects, but risks are small.

\subsubsection{Atomoxetine}

ATX yields moderate efficacy in reducing ADHD symptoms (SMD: -0.33 to -0.40 ) [227]. Onset of action is $1-2$ weeks, and full effects may take up to 6 months to develop [250]. If rapid onset of effect is not essential, ATX may be a good choice for high risk patients who need stable control of ADHD symptoms [251].

The use of ATX as first line in drug abusers continues to be debated with other experts preferring stimulants due to rapid onset and potentially greater effects [252]. Although in the past there were concerns that stimulants may increase the risk of substance use disorders (SUD), there is now a wealth of data demonstrating reductions in SUD during periods of treatment of ADHD with stimulants [233,253].

ATX may be a good choice with co-occurring anxiety that might be exacerbated by stimulants, as a RCT of adults with comorbid ADHD and social anxiety disorder found improvements in both ADHD and social anxiety [254]. ATX does not appear to be effective in the treatment of comorbid depression in adolescents [255].

\subsubsection{Guanfacine and clonidine}

In Europe, guanfacine extended-release (GXR), an alfa-2 adrenergic agonist, is licensed for the treatment of children and adolescents with ADHD for whom stimulants are not suitable, not tolerated or where shown to be ineffective [256,257]. Notably, there are currently no RCTs in adult patients to support the use of GXR in this age group, only a study using GXR or placebo as an adjunct to stimulant treatment that had insufficient effect. Both treatments did not differ in efficacy [258].

Extended-release (ER) clonidine is approved in the US for treatment of ADHD in 6-17- year olds as monotherapy or an adjunct to stimulants. There are RCTs on both ER clonidine $[259,260]$ and IR clonidine [261,262] in children and adolescents with ADHD, but no equivalent studies in adults.

\subsubsection{Bupropion}

There are conflicting findings for bupropion from a small number of adult studies. Positive results were reported with higher doses (400-450 mg per day) [263,264]. Due to a limited evidence base, bupropion use should be restricted to cases who do not tolerate other ADHD medications.

\subsubsection{Other medications}

Selective noradrenaline reuptake inhibitors such as reboxetine may be an alternative to ATX $[265,266]$. There is limited evidence for tricyclic antidepressants [267,268]. Selective serotonin reuptake inhibitors (SSRIs) are not effective for the treatment of ADHD $[229,230,269]$. Modafinil, a wakefulness-promoting agent used in the treatment of narcolepsy, has not been demonstrated as an effective treatment for adult ADHD in a phase 3 trial that had high rates of side effects (86\%) and drop-out (47\%) possibly resulting from excessive doses (210-510 mg/day) [270].

\subsubsection{Long-term safety concerns}

Currently there is no evidence of significant long-term risks using stimulants. Tomography scans find higher striatal dopamine transporter availability in ADHD patients treated with stimulants [271]. The clinical implications of this up-regulation are not clear. Potential toxicity on heart valves of medications with an agonist 
effect on 5- $\mathrm{HT}_{2 \mathrm{~B}}$ receptors have been discussed [272], including $\mathrm{MPH}$ and guanfacine. Some argue that echocardiography should be routinely performed prior to treatment with potential valvulopathic drugs [273]. This risk is not however established, and we and others do not recommend routine echocardiograms [184,252,274], except in older adults ( $>$ age 50) [167].

\subsubsection{Combined psychopharmacology}

The high rate of psychiatric comorbidity in adult ADHD frequently necessitates combined psychopharmacology [275]. Accordingly, the risk of possible drug-drug interactions when treating adults with ADHD must be considered. These include the following:

- Monoamine oxidase inhibitors are generally contraindicated due to the risk of hypertensive crisis.

- Although MPH is mainly metabolized in the liver, drug interactions via CYP enzymes are uncommon. Amphetamines, however, are metabolized primarily via the CYP 2D6 enzyme system making drug interactions possible (with inhibitors or inducers of this enzyme system, e.g. fluoxetine and paroxetine) [276].

- Treatment with medications that act on the noradrenaline system, including certain antidepressants (e.g. duloxetine, venlafaxine), will have an additive effect and may increase the risk of hypertension and other adverse cardiovascular events.

- Due to its metabolism by the CYP 2D6 enzyme system, ATX levels can increase in combination with enzyme-inhibiting SSRIs (e.g. fluoxetine and paroxetine) [277].

\subsection{Considerations when treating special groups with pharmacotherapy}

\subsubsection{ADHD with comorbid bipolar disorder}

A pharmaco-epidemiological study found that MPH monotherapy in patients with bipolar disorder increased the risk of switch to a manic episode (hazard ratio 6.7). However, when combined with a mood stabilizer, MPH reduced the risk of mania (hazard ratio 0.6) [278]. This supports the current recommendation to treat ADHD in bipolar disorder patients with stimulants, so long as they are also taking mood stabilizers.

\subsubsection{ADHD with comorbid substance use}

Meta-analysis of RCTs in adults found that most ADHD medications reduce the core symptom severity of ADHD, but have limited effect on comorbid substance use [279]. However, a large Danish Registry study showed a decrease of substance use in ADHD patients when using MPH [280]. Recent RCTs using higher doses of ER Mixed Amphetamine Salts (Adderall XR®) or OROS MPH (Concerta $\AA$ ), combined with CBT found better effects on both ADHD and substance use, compared to studies using lower dosages [281,282]. The relevance of higher doses is supported by a pharmaco-epidemiological study from Sweden showing that higher $\mathrm{MPH}$ dose was associated with long-term treatment adherence in patients with ADHD and substance use disorders (SUD) [283]. Immediate-release stimulants should be avoided in patients with ADHD and SUD, whereas OROS-MPH and LDX have lower abuse potential [284]. Further recommendations for treating comorbid substance use disorders can be found in Bolea-Alamanac et al. [184], and in the recently published international Consensus Statement on diagnosis and treatment of substance use disorders with comorbid ADHD [285]. This Consensus Statement mentions that the use of stimulant treatment for ADHD does not precipitate the onset of SUD in adults without previous SUD [286]; also that in SUD patients, treatment of ADHD can be useful to reduce ADHD symptoms without worsening the SUD, and should not be avoided [287].

\subsubsection{Cognitive enhancement in students}

Another group where screening for ADHD is appropriate is the student population. This is because we know that ADHD specially interferes with educational attainment. Further, this has been highlighted be the finding that genetic risks for ADHD overlap with those for educational outcomes [28]. Student groups with particularly high rates of ADHD include those presenting with specific learning difficulties [288] and mental health problems [202]. Related to this, there are concerns, particularly in countries with a higher rate of stimulant prescriptions, that students may seek the diagnosis of ADHD to receive stimulants for cognitive enhancement. Some studies show that although most students use their ADHD medication as prescribed, misuse and diversion is not uncommon [289]. Care must therefore be taken to ensure that students are diagnosed and treated for ADHD when appropriate, while minimising risks of diversion.

\subsubsection{Pregnancy and breastfeeding}

There is only limited information on the effects of ADHD medication on the fetus and new-born [290]. As suggested by population-based studies, MPH or amphetamine exposure during pregnancy is not related to higher rates of any congenital malformations [291-293]. For cardiac malformations, MPH use was associated with a small increased risk (RR 1.28 (95\% CI, 0.941.74), where amphetamines were not. There is some evidence suggesting that treatment with MPH or ATX might increase the risk of miscarriage [294,295], although there were several confounding factors such as younger age and social disadvantage, that could explain the association [296]. Another study found that the use of stimulant medication during pregnancy is associated with miscarriage to the same degree as having ADHD itself [295], these findings need further investigation. Potential adverse effects on the fetus from intra placental exposure to medication in pregnancy should be considered against the possible adverse effects of interrupting treatment abruptly in women with ADHD [184,297,298]. Each case should be assessed individually taking into account possible risks of both treating and interrupting treatment.

Amphetamines may be given preference over other medications. Some authors do not consider Atomoxetine because of lack of safety data [299,300]. MPH seems to be safe during breastfeeding. The amounts of medication excreted in breast milk, and consumed by the infant, are very small (with the Relative Infant Dose (RID) (< $1 \%$ ) $[290,299]$, and no drug-related side effects have been were reported. The impact of ATX, guanfacine, and clonidine on breastfeeding-related outcomes is largely unknown [301-303], and they are not recommended [299].

Until now no adverse reactions were reported among infants of mothers receiving LDX or dexamphetamine (RID: 4-10.6\%). There are some preliminary reports suggesting that dexamphetamine treatment may lead to a suppression of prolactin secretion in postpartum women, though with unclear clinical implications [304]. Bupropion was found to produce low levels in milk, suggesting relative safety. Of note, there are two known cases of seizures developed by children breastfed by women receiving bupropion [305].

\subsubsection{ADHD and sleep problems}

In the majority of cases, ADHD in children and adults is associated with a circadian rhythm disorder with delayed sleep onset [306-308]. Meta-analysis of nine studies investigating the effects of stimulant medication on sleep in children and adolescents found that stimulants can lead to longer sleep latency, 
worse sleep efficiency, and shorter sleep duration [309]. Similar findings have been reported in adults [310]. Careful titration of stimulants and psychoeducation around sleep optimization can improve the quality of sleep, possibly due to improved daytime structure, the maintenance of regular physical activity and improved mood [198,309,311]. In children with ADHD and chronic insomnia, melatonin has been shown to advance the sleep onset, and increase sleep duration [312]. A trial targeting insomnia in adults with ADHD is ongoing, and clinical experience points in the same direction of possible efficacy of treatment with melatonin at night, and also of light therapy in the morning [308]. Treatment of insomnia should always start with sleep hygiene education and optimizing the stimulant or non-stimulant treatment of ADHD [311]. A low dose of IR MPH (usually $5 \mathrm{mg}$ ) taken at night time can reduce ceaseless mental activity to a degree that allows sleep in some cases.

\subsection{Cognitive behavior therapy (CBT) and coaching for $A D H D$}

Although pharmacological treatment of ADHD is very effective, many patients continue to experience significant symptoms and functional impairment in daily living. Empirical evidence from numerous uncontrolled studies, more than ten randomized controlled trials (RCTs) and a meta-analysis has shown that in group or individual settings, cognitive behavioral therapy (CBT) reduces ADHD-core symptoms, associated symptoms such as emotion dysregulation, anxiety and depression, and functional impairments across different areas of daily living in adults [228,313-315]. CBT is best used within a multi-modal treatment approach and as an adjunct to medication as current research does not fully support the efficacy of CBT as a sole treatment for adult ADHD [274,316-318]. Most controlled studies have been conducted in patients taking ADHD medication and demonstrate an additional significant treatment effect [313,318-322]. The largest controlled multi-center CBT-study to date has demonstrated that psychological interventions result in better outcomes when combined with MPH as compared to psychological interventions in unmedicated patients [228]. In a systematic review of 51 pharmacological and non-pharmacological interventions [316], the highest proportion of improved outcomes (83\%) was for patients receiving combination treatment. However, not all adults with ADHD desire or tolerate pharmacological treatment. In these cases CBT may be the best option.

Across all studies there are some consistent characteristics of CBT treatment, both in form and content. All approaches are highly structured. Most are manualized, and establish psychoeducation as the first step. Most programs are skills-based and focus on organizational and time management skills, emotional regulation/ control, problem solving skills, prosocial competence and strategies to improve attention and impulsivity management. In addition to behavioral interventions that require patients to try out and rehearse in daily life techniques suggested in the therapy session, programs include cognitive strategies, such as the identification of negative automatic thoughts, methods to address 'thinking errors' and the introduction of cognitive restructuring techniques [323]. There is emerging evidence that cognitive distortions and dysfunctional cognitive schemes related to a biographic accumulation of negative experiences associated with ADHD-symptoms contribute to negative functional outcomes and lead to avoidance behavior, failure-orientation, reduced self-efficacy, procrastination, depressive symptoms and anxiety [324-326]. Furthermore, most programs highlight the importance of including significant others in the treatment process to reduce dysfunctional interactions and stigmatization associated with ADHD symptoms.

Coaching or mentoring is a derivative of the cognitive behavioral paradigm involving the development of a collaborative mentoring partnership. Coaching aims to provide structure, support and feedback for building life skills and changing negative outcomes related to ADHD in daily living [217,327,328]. However, there is no standard methodology and the coaching process varies considerably, including face-to-face contact, telephone calls and/ or email contact. To date, there are no controlled studies assessing the efficacy of coaching as a therapeutic means in the treatment of adults with ADHD. Nevertheless there is some preliminary support for positive outcomes from uncontrolled studies [327,328]. Similarly there is some support for the effectiveness of mindfulness based cognitive therapy (MBCT) for adults with ADHD [329-331].

\section{Cost and cost effectiveness}

Because of the broad impact of ADHD on general functioning, the disorder is likely to have serious economic implications for children, families, and society. The studies which calculate costs however are so far limited as they typically examine only one aspect of the costs, for example "from the perspective of a major German health insurance fund" [332]. Particularly for adults with ADHD, estimates should include not only direct costs (the costs of labor, supplies, and equipment to provide direct patient care services) but also indirect costs (mainly related to the loss of productivity) such as costs to family, costs due to impairment in employment, costs due to accidents [333], smoking and substance misuse, and costs due to involvement with the criminal justice system.

Direct costs have been examined [334-336], but are heavily depending on the healthcare system from which they are derived and the type of pathway/care package provided. These estimates therefore, although potentially useful for comparisons between disorders within the same healthcare system, should not be generalized to different contexts. The most comprehensive approach to calculate the total costs of ADHD in the Danish Psychiatric Central Register, showed that there is an economic burden of ADHD which is considerable and falls both on the individual and the state [337].

Apart from the costs (either direct or indirect) of ADHD, there is also the question of cost benefit for treating ADHD. This first asks whether a treatment of a disorder is worthwhile when compared against alternatives in terms of allocation of healthcare funds, and second which ADHD intervention brings the most benefit at the lowest cost. For the former, an argument can be made that adult ADHD is a condition which is cost effective to treat from the societal perspective because of the efficacy and relatively low cost of the medicines used for its treatment [224,338]. For the latter, among children and adolescents with ADHD, there is consistent evidence [339-343] that pharmacotherapies are cost effective compared with no treatment or behavioral therapy [344]. Unfortunately there is insufficient research to conclude the same for adults with ADHD (Table 3 ).

\section{Stigma surrounding ADHD}

Substantial stigmatization and myths continue to surround ADHD [345]. A recent study on negative coverage of ADHD and autism in Flemish newspapers found a 2-fold more negative than neutral or positive coverage of ADHD than of autism [346]. Stigma arises from lack of awareness, of prejudice about symptom etiology (e.g. poor parenting, lack of moral), incompetence (e.g. laziness) and perceived dangerousness (e.g. unpredictable and potentially violent behavior) [347]. Other variables contributing to stigma are doubts about the validity and reliability of an ADHD diagnosis, along with age, gender, ethnicity and the public's skepticism toward ADHD medication. Also, the restricted regulatory status for 
Table 3

Summary of key points.

Neurobiological and High heritability (60-80\%), environmental risk factors and their interaction, are involved in the majority of ADHD cases.
environmental

background

Abnormalities in grey matter, cortical thickness and white matter microstructure have been shown in ADHD compared to controls, indicating that structural deficits in ADHD involve interconnections among large scale brain networks.

Functional neuroimaging shows dysfunctions in several domain-specific fronto-striatal and fronto-cerebellar neural networks, as well as an enhanced activation of default mode regions.

These findings, as well as the effectiveness of pharmacological treatments with dopamine agonists, support the neurobiological underpinnings of ADHD.

Diagnosis The clinical diagnosis of ADHD depends on self-report during a structured diagnostic interview, whenever possible with collateral information about lifetime symptoms and impairment. It cannot be established using solely neuropsychological tests.

Recent research shows that besides inattention, hyperactivity and impulsivity, emotional dysregulation and excessive mind wandering are common symptoms associated with ADHD in adults.

The underdiagnosis of girls and women with ADHD may be due to a different expression of symptoms and comorbidities, to referral bias, and to interaction of hormones with the dopaminergic system. Further research is needed.

The concept of late-onset ADHD refers to an age of onset after 12 years, and needs further study concerning the overlap and differences with childhood onset ADHD.

High rates of psychiatric comorbidity, physical multi-morbidity, increased mortality and suicide rates, and criminality may 'mask' the underlying ADHD condition.

Stigma leads to misconceptions about ADHD and underdiagnosis.
Main changes in the DSM-5 criteria for ADHD are:
ADHD is placed in the chapter of Neurodevelopmental Disorders
The age of onset of symptoms is before age 12 , instead of age 7
The cut off for current symptoms in adults is $5 / 9$ instead of $6 / 9$
A diagnosis of ADHD can now be combined with Autism Spectrum Disorder (ASD)

Prevalence $\quad$ The mean prevalence of ADHD in adults across 20 countries is estimated at $2.8 \%$. In people above age 60 , a similar prevalence rate has been found.

The prevalence of ADHD in prisons is 25\%, a 10-fold increase compared to the general population.

Transition Two-thirds of children with ADHD continue to have ADHD symptoms associated with impairments in adulthood, therefore adjustments in the health care system to support the transition from child to adult services are needed.

Treatment Psychoeducation for adults with ADHD and their significant others is recommended as a first treatment step.

Stimulants are the treatment of choice for adults with ADHD. Long-lasting, extended release formulations are preferred for reasons of adherence to treatment, for the protection against abuse, to avoid rebound symptoms, for safer driving, and to provide cover throughout the day without the need for multiple dosing.

Licensing of stimulants for adult ADHD is urgently needed in European countries and beyond.

The non-stimulant atomoxetine is recommended as a second line treatment. There is limited evidence in adults for guanfacine, bupropion, tricyclic antidepressants and reboxetine in controlled studies.

Cognitive Behavior Therapy reduces ADHD-core symptoms, associated symptoms such as emotion dysregulation, anxiety and depression, and functional impairments across different areas of daily living in adults. CBT is best used within a multi-modal treatment approach and as an adjunct to medication, as research does not fully support the efficacy of CBT as a sole treatment for adult ADHD.

Pharmacological

treatment

of special groups

In patients with ADHD and substance use disorder, to be effective, treatment with stimulants may use higher dosages than normal.

In patients with ADHD and bipolar disorder, the combined approach of a mood stabilizer with a stimulant has been shown to treat both disorders effectively without inducing (hypo)manic states.

During pregnancy stimulants are not advised, though large cohort data showed no increased risk for congenital malformations using stimulants during the first trimester. The risk for cardiac malformations using MPH however was slightly increased, while this was not the case for amphetamines.

Research on the wishes of older people with ADHD regarding treatment, and trials on the safety and efficacy of medicines are needed. Based on data from large cohort studies, following treatment, the negative outcomes associated with ADHD significantly diminish, i.e. traffic accidents, mortality, criminality, depression and suicide, and substance abuse.

Costs The economic burden of ADHD is considerable and falls both on the individual and the state. Pharmacotherapy in children is cost effective compared to no treatment and behavioral therapy, but data in adults are still lacking.

ADHD medications in many countries adds to the stigma within the mental health profession and the media. Public stigmatization of ADHD, and the following self-stigma and courtesy stigma are underestimated risk factors for treatment adherence, treatment efficacy, symptom aggravation, life satisfaction, and mental wellbeing of individuals affected by ADHD [348].

Self-stigma has been studied in children and adolescents and is characterized by a sense of feeling different from peers, and negative self-evaluation as a consequence of that perception. However, some young people were prepared to challenge the stigma by self-disclosure and openness about their condition [349]. Lower stigma in teachers towards adult ADHD seems to relate to greater knowledge about the condition [350]. Among general practitioners (GPs) from the UK, Europe and Australia, there is mixed and often unhelpful attitudes regarding the validity of ADHD as a construct, the role of medication and how parenting contributes to the presentation [351]. A paucity of training was identified, alongside a reluctance of GPs to become involved in shared care practice. If access to services is to be improved for people with ADHD, there needs to be a focused and collaborative approach to training [351].

\subsection{Combatting stigma}

Disclosure of mental health problems can be a challenge [352], but an increasing number of celebrities have cast aside stigma by revealing they had ADHD and, in some cases, have been pharmacologically treated for many years (https://www.additudemag.com/successful-people-with-adhd-learning-disabilities/). This is of course supportive for patients but it is strongly recommended that psychoeducation about ADHD should be included in anti-stigma programs [347]. Of note, adult ADHD is rarely included in college programs for medical and psychology students, or in the training of professionals working in adult 
mental health services. This contributes to misconceptions, underdiagnosis and undertreatment among professionals [2,3]. Psychoeducation programs therefore need to target all clinical disciplines at all stages of professional development (e.g. from students through to primary and secondary care physicians, psychologists and nurses) to ensure that appropriate early recognition, diagnosis and treatment is provided.

Internationally recognized guidelines are available on the assessment, treatment and management of adults with ADHD, as well as the development and provision of clinical services [182,184,274,353]. The current lack of licensed indications for the use of stimulants in adults in most European countries (but not in the US or Canada) is not supported by available data, but rather results from the outdated focus that ADHD is a 'child disorder', caution from regulators regarding potential cardiovascular side effects, and commercial manipulation by the pharmaceutical industry. In Europe, this situation may change in the coming years as formulations of methylphenidate and dexamphetamine are being put forward for registration.

Stigma prevents patients to ask for help and increases their suffering and impairment. Hence the successful management of ADHD by prescribers will include an awareness of the potential stigma that may be perceived by the patient and its consequences on treatment initiation and maintenance. The only way to reduce stigma surrounding ADHD is community, health and education systems in Europe and beyond working together by education of professionals and the public, and by a unified licensing of medications for ADHD in adults.

\section{Conclusions}

This consensus statement reflects agreement on the state of ADHD, but by definition it is provisional. It does not negate the ongoing scientific debate in the field and the different opinions and hypotheses about adult ADHD among experts. Yet none of that undercuts the legitimacy or validity of the construct, or of the conclusions one can make about the current status of the consistency of the evidence. ADHD is a neurodevelopmental and heritable disorder with a lifespan perspective: starting in childhood, persisting in adulthood until old age, with significant psychosocial impairment, a high comorbidity rate and multimorbidity. It is associated with high levels of personal distress, and a substantial economic burden for society if left unidentified and untreated. DSM-5 has changed some of the criteria that facilitate the diagnosis in adolescents and adults. Assessment should include a detailed account of the developmental history, of both current and retrospective ADHD symptoms and impairment, and associated comorbidities. To prevent under-reporting of symptoms, external validation is desirable by collateral information. Multimodal treatment is required, comprising of psychoeducation, pharmacotherapy, and cognitive behavior therapy and/or coaching. Psychoeducational European programs to combat stigma and to inform the public and (mental) health professionals about new knowledge on the lifespan perspective of ADHD are needed to improve and increase diagnostic and treatment services for adult ADHD. Research on the different presentation of ADHD in women, and on treatment of ADHD in old age should be further developed in order to improve their treatment options.

\section{Conflicts of interest}

Kooij, J.J.S.: No conflict of interest. Bijlenga, D.: No conflict of interest. Salerno, L.: No conflict of interest. Jaeschke, R.: No conflict of interest. Bitter I.: Honoraria or consultation fees from EGIS, EGRIS, Eli Lilly, Gedeon Richter, Janssen/Janssen-Cilag, Lundbeck, MedAvante, Pierre Fabre, PSI (CRO) and Servier. Balázs, J.: No conflict of interest. Thome, J.: No conflict of interest. Dom, G.: No conflict of interest. Kasper, S.: Grants/research support, consulting fees and/or honoraria within the last three years from Angelini, AOP Orphan Pharmaceuticals AG, AstraZeneca, Eli Lilly, Janssen, KRKAPharma, Lundbeck, Neuraxpharm, Pfizer, Pierre Fabre, Schwabe and Servier. Nunes Filipe, C.: No conflict of interest. Stes, S.: Principal Investigator before 2016 in studies funded by JanssenCilag, Lilly and Novartis; speaker fees and advisory board for Lilly, Novartis, Janssen-Cilag, and Shire. Since 2016 no conflicts of interest. Mohr. P.: consultant and speaker for Eli Lilly, JanssenCilag, and Lundbeck. Leppämäki, S.: No conflict of interest. Casas, M.: speaker fees from Janssen- Cilag, Bristol-Mayers Squibb, FerrerBrainfarma, Pfizer, Lundbeck, Otsuka, Servier, Lilly, Shire, GSK, Rovi and Adamed. Advisory board for Janssen-Cilag, Lilly, and Shire. Bobes, J.: research grants and/or consultant, advisor or speaker within de last 3 years for: AB-Biotics, Acadia Pharmaceuticals, Casen Recordati, D\&A Pharma, Gilead, Ferrer, Hoffman La Roche, Indivior, Janssen-Cilag, Indivior, Lundbeck, Mundipharma, Otsuka, Pfizer, Reckitt-Benckiser, Servier and Shire, research funding from the Spanish Ministry of Economy and Competiveness - Centro de Investigación Biomedica en Red area de Salud Mental (CIBERSAM) and Instituto de Salud Carlos III, Spanish Ministry of Health, Social Services and Equality - Plan Nacional sobre Drogas- and the 7th Framework Program of the European Union. McCarthy, J.M.: No conflict of interest. Kjems Philipsen, A.: No conflict of interest. Pehlivanidis, A.: No conflict of interest. Niemela, A.: No conflict of interest. Bolea-Alamanac, B.: Honoraria on one occasion for an educational lecture for Janssen pharmaceuticals. Edvinsson, D.: No conflict of interest. Baeyens, D.: No conflict of interest. Wynchank, D.: Advisory boards of Janssen BV, Novartis and Eli Lilly for activities outside the scope of this paper (2009-2014). Sobanski, E.: lectures paid by Shire within the last two years. Philipsen, A.: Advisory boards, lectures, performed phase 5 studies, or travel grants within the last 5 years from Eli Lilly and Co, Janssen-Cilag, Lundbeck, MEDICE Arzneimittel, Pütter GmbH and Co KG, Novartis, Servier, and Shire; and has authored books and articles on ADHD published by Elsevier, Hogrefe, Oxford Press, Schattauer, Kohlhammer, Karger, and Springer. McNicholas, F.: Received an unrestricted educational grant from Shire Pharmaceuticals in 2016, and grant support for a UCD Newman Fellow 2014-2015. Caci, H.: No conflict of interest. Manor, I.: Honoraria, counseling and advisory boards for Jansen-Cilag, Israel, Teva Israel, Novartis Israel, Medison Israel. Asking for a research grant: Shire. Krause, J.: No conflict of interest. Fayyad, J.: No conflict of interest. RamosQuiroga, J.A.: speakers' bureau and/or consultant for Eli-Lilly, Janssen-Cilag, Novartis, Shire, Lundbeck, Almirall, Braingaze, Sincrolab, and Rubió in the last 5 years. Travel awards (air tickets + hotel) for meetings from Janssen-Cilag, Rubió, Shire, and Eli- Lilly. The Department of Psychiatry chaired by him received unrestricted educational and research support in the last 5 years from: Eli-Lilly, Lundbeck, Janssen- Cilag, Actelion, Shire, Ferrer, and Rubió. Foeken, K.: No conflict of interest. Adamou, M.: No conflict of interest. Ohlmeier, M.: No conflict of interest. Fitzgerald, M.: No conflict of interest. Gill, M.: No conflict of interest. Lensing, M.: Noconflict of interest. Motavalli Mukaddes, N.: advisor and speaker of Sanofi Drug Company. Brudkiewicz, P.: No conflict of interest. Gustafsson, P.: Former member of advisory board for Lilly, advisory board for Elvanse and Intunive (Shire). Tani, P.: No conflict of interest. Oswald, P.: No conflict of interest. Carpentier, P.J.: No conflict of interest. De Rossi, P.: No conflict of interest. Delorme, R.: No conflict of interest. Markovska Simoska, S.: No conflict of interest. Pallanti, S.: No conflict of interest. Young, S.: Honoraria for consultancy, travel, educational talks and/or research from Janssen, Eli Lilly, HB Pharma, and/or Shire. She is author of the Young-Bramham CBT Programme. Lehtonen, T. No conflict of interest. Hirvikoski, T.: no conflict of interest related to this article. Royalties for text books and manuals 
from Hogrefe. Pironti, V.: No conflict of interest. Ginsberg, Y.: Speaker fees, reimbursement for travel costs and/or consultant for Novartis, HB Pharma, Shire, Eli Lilly, Hogrefe, Broadman Clarke Partners, Medscape, Medibas and Natur \& Kultur. Félegyházy, Z.: No conflict of interest. Richarte, V.: Speakers' bureau for Eli-Lilly, Shire in the last 5 years. Travel awards (air tickets + hotel) for psychiatric meetings from Shire. The Department of Psychiatry received unrestricted educational and research support in the last 5 years from: Eli-Lilly, Lundbeck, Janssen- Cilag, Actelion, Shire, Ferrer, and Rubió. Kustow, $\mathrm{J}$.: Consultancy services to Eli Lilly and Shire and speaker fees from Eli Lilly, Jansen Cilag and Shire. Müller, U.: Advisory board / consultancy fees or speaker honorarium from Eli Lilly, Heptares and Shire, Educational grants / travel expenses from Eli Lilly, Flynn Pharma / Medice, Janssen-Cilag, Lundbeck, Shire and Sunovion (all United Kingdom). Bejerot, S.: No conflict of interest. Semerci, B.: No conflict of interest. Dobrescu, I.: No conflict of interest. Styr, B.: No conflict of interest. Rad, F.: No conflict of interest. Mihailescu, I.: No conflict of interest. Garcia-Portilla, M.P.: No conflict of interest. Asherson, P.: Kings College London research support account for Asherson received honoraria for consultancy to Shire, Eli-Lilly and Novartis; educational/research awards from Shire, Lilly, Novartis, Vifor Pharma, GW Pharma and QbTech; speaker at sponsored events for Shire, Lilly and Novartis.

\section{Acknowledgement}

This project did not receive any financial support from funding agencies in the public, commercial, or not-for-profit sectors.

\section{References}

[1] Kooij SJ, Bejerot S, Blackwell A, Caci H, Casas-Brugue M, Carpentier PJ, et al. European consensus statement on diagnosis and treatment of adult ADHD: The European Network Adult ADHD. BMC Psychiatry 2010;10:67.

[2] Asherson P, Buitelaar J, Faraone SV, Rohde LA. Adult attention-deficit hyperactivity disorder: key conceptual issues. Lancet Psychiatry 2016;3 (6):568-78.

[3] Fayyad J, Sampson NA, Hwang I, Adamowski T, Aguilar-Gaxiola S, AlHamzawi A, et al. The descriptive epidemiology of DSM-IV adult ADHD in the world health organization world mental health surveys. Atten Defic Hyperact Disord 2017;9(1):47-65.

[4] Faraone SV, Doyle AE. The nature and heritability of attention-deficit/hyperactivity disorder. Child Adolesc Psychiatr Clin North Am 2001;10(2) 299-2ix.

[5] Faraone SV. Genetics of adult attention-deficit/hyperactivity disorder. Psychiatr Clin North Am 2004;27:303-21.

[6] Sprich S, Biederman J, Crawford MH, Mundy E, Faraone SV. Adoptive and biological families of children and adolescents with ADHD. J Am Acad Child Adolesc Psychiatry 2000;39(11):1432-7.

[7] Moore J, Fombonne E. Psychopathology in adopted and nonadopted children: a clinical sample. Am J Orthopsychiatry 1999;69(3):403-9.

[8] Gilger JW, Pennington BF, DeFries JC. A twin study of the etiology of comorbidity: attention-deficit hyperactivity disorder and dyslexia. JAmAcadChild AdolescPsychiatry. 1992;31(2):343-8.

[9] Sherman DK, Iacono WG, McGue MK. Attention-deficit hyperactivity disorder dimensions: a twin study of inattention and impulsivity-hyperactivity. JAmAcadChild AdolescPsychiatry. 1997;36(6):745-53.

[10] Rietveld MJ, Hudziak JJ, Bartels Mv B, C.E, Boomsma DI. Heritability of attention problems in children: longitudinal results from a study of twins, age 3 to 12. J Child Psychol Psychiatry 2004;45(3):577-88.

[11] Levy F, Hay DA, McStephen M, Wood C, Waldman I. Attention-deficit hyperactivity disorder: a category or a continuum? Genetic analysis of a large-scale twin study. J Am Acad Child Adolesc Psychiatry 1997;36(6):737-44.

[12] Faraone SV, Perlis RH, Doyle AE, Smoller JW, Goralnick JJ, Holmgren MA, et al. Molecular genetics of attention-deficit/hyperactivity disorder. Biol Psychiatry 2005;57(11):1313-23.

[13] Stevens SE, Sonuga-Barke EJ, Kreppner JM, Beckett C, Castle J, Colvert E, et al. Inattention/overactivity following early severe institutional deprivation: presentation and associations in early adolescence. J Abnorm Child Psychol 2008;36(3):385-98.

[14] Faraone SV, Biederman J, Monuteaux MC. Toward guidelines for pedigree selection in genetic studies of attention deficit hyperactivity disorder. Genet Epidemiol 2000;18(1):1-16.

[15] Boomsma DI, Saviouk V, Hottenga JJ, Distel MA, de Moor MH, Vink JM, et al. Genetic epidemiology of attention deficit hyperactivity disorder (ADHD index) in adults. PLoS One 2010;5(5)e10621.
[16] van den Berg SM, Willemsen G, de Geus EJ, Boomsma DI. Genetic etiology of stability of attention problems in young adulthood. Am J Med Genet B Neuropsychiatr Genet 2006;141B(1):55-60.

[17] Larsson H, Asherson P, Chang Z, Ljung T, Friedrichs B, Larsson JO, et al. Genetic and environmental influences on adult attention deficit hyperactivity disorder symptoms: a large Swedish population-based study of twins. Psychol Med 2013;43(1):197-207.

[18] Brikell I, Kuja-Halkola R, Larsson H. Heritability of attention-deficit hyperactivity disorder in adults. Am J Med Genet B Neuropsychiatr Genet 2015.

[19] Merwood A, Greven CU, Price TS, Rijsdijk F, Kuntsi J, McLoughlin G, et al Different heritabilities but shared etiological influences for parent, teacher and self-ratings of ADHD symptoms: an adolescent twin study. Psychol Med (Paris) 2013;43(9):1973-84.

[20] Chang Z, Lichtenstein P, Asherson PJ, Larsson H. Developmental twin study of attention problems: high heritabilities throughout development. JAMA Psychiatry 2013;70(3):311-8.

[21] Larsson H, Chang Z, D'Onofrio BM, Lichtenstein P. The heritability of clinically diagnosed attention deficit hyperactivity disorder across the lifespan. Psychol Med (Paris) 2013;1-7.

[22] Faraone SV, Larsson H. Genetics of attention deficit hyperactivity disorder Mol Psychiatry 2018.

[23] Li D, Sham PC, Owen MJ, He L. Meta-analysis shows significant association between dopamine system genes and attention deficit hyperactivity disorder (ADHD). Hum Mol Genet 2006;15(14):2276-84.

[24] Gizer IR, Ficks C, Waldman ID. Candidate gene studies of ADHD: a metaanalytic review. Hum Genet 2009;126(1):51-90.

[25] Kuntsi J, Neale BM, Chen W, Faraone SV, Asherson P. The IMAGE project: methodological issues for the molecular genetic analysis of ADHD. Behav Brain Funct 2006;2:27.

[26] Neale BM, Medland SE, Ripke S, Asherson P, Franke B, Lesch KP, et al. Metaanalysis of genome-wide association studies of attention-deficit/hyperactivity disorder. J Am Acad Child Adolesc Psychiatry 2010;49(9):884-97.

[27] Poelmans G, Pauls DL, Buitelaar JK, Franke B. Integrated genome-wide association study findings: identification of a neurodevelopmental network for attention deficit hyperactivity disorder. Am J Psychiatry 2011;168 (4):365-77.

[28] Demontis D, Walters RK, Martin J, Mattheisen M, Als TD, Agerbo E, et al. Discovery of the first genome-wide significant risk loci for ADHD. Nat Genet 2018 In Press.

[29] Ribases M, Sanchez-Mora C, Ramos-Quiroga JA, Bosch R, Gomez N, Nogueira $\mathrm{M}$, et al. An association study of sequence variants in the forkhead box P2 (FOXP2) gene and adulthood attention-deficit/hyperactivity disorder in two European samples. Psychiatr Genet 2012;22(4):155-60.

[30] Middeldorp CM, Hammerschlag AR, Ouwens KG, Groen-Blokhuis MM Pourcain BS, Greven CU, et al. A genome-wide association meta-analysis of Attention-Deficit/Hyperactivity disorder symptoms in population-based pediatric cohorts. J Am Acad Child Adolesc Psychiatry 2016;55(10)896-905 e6.

[31] Elia J, Gai X, Xie HM, Perin JC, Geiger E, Glessner JT, et al. Rare structural variants found in attention-deficit hyperactivity disorder are preferentially associated with neurodevelopmental genes. Mol Psychiatry 2009;15(6):637-46.

[32] Williams NM, Zaharieva I, Martin A, Langley K, Mantripragada K, Fossdal R, et al. Rare chromosomal deletions and duplications in attention-deficit hyperactivity disorder: a genome-wide analysis. Lancet 2010;376(9750):1401-8.

[33] Williams NM, Franke B, Mick E, Anney RJ, Freitag CM, Gill M, et al. Genomewide analysis of copy number variants in attention deficit/hyperactivity disorder confirms the role of rare variants and implicates duplications at 15q13.3. Am J Psychiatry 2012;169(2):195-204.

[34] Elia J, Glessner JT, Wang K, Takahashi N, Shtir CJ, Hadley D, et al. Genomewide copy number variation study associates metabotropic glutamate receptor gene networks with attention deficit hyperactivity disorder. Nat Genet 2012;44(1):78-84.

[35] Lesch KP, Selch S, Renner TJ, Jacob C, Nguyen TT, Hahn T, et al. Genome-wide copy number variation analysis in attention-deficit/hyperactivity disorder: association with neuropeptide $\mathrm{Y}$ gene dosage in an extended pedigree. Mol Psychiatry 2011;16(5):491-503.

[36] Franke B, Hoogman M, Arias Vasquez A, Heister JG, Savelkoul PJ, Naber M, et al. Association of the dopamine transporter (SLC6A3/DAT1) gene 9-6 haplotype with adult ADHD. Am J Med Genet B Neuropsychiatr Genet 2008; $147 \mathrm{~B}(8): 1576-9$

[37] Johansson S, Halmoy A, Mavroconstanti T, Jacobsen KK, Landaas ET, Reif A et al. Common variants in the TPH1 and TPH2 regions are not associated with persistent ADHD in a combined sample of 1,636 adult cases and 1,923 controls from four European populations. Am J Med Genet B Neuropsychiat Genet 2010;153B(5):1008-15.

[38] Ribases M, Hervas A, Ramos-Quiroga JA, Bosch R, Bielsa A, Gastaminza X, et al Association study of 10 genes encoding neurotrophic factors and their receptors in adult and child attention-deficit/hyperactivity disorder. Biol Psychiatry 2008;63(10):935-45.

[39] Ribases M, Ramos-Quiroga JA, Hervas A, Bosch R, Bielsa A, Gastaminza X, et al Exploration of 19 serotoninergic candidate genes in adults and children with attention-deficit/hyperactivity disorder identifies association for 5HT2A, DDC and MAOB. Mol Psychiatry 2009;14(1):71-85.

[40] Franke B, Faraone SV, Asherson P, Buitelaar J, Bau CH, Ramos-Quiroga JA, et al The genetics of attention deficit/hyperactivity disorder in adults, a review. Mol Psychiatry 2012;17(10):960-87. 
[41] Landaas ET, Johansson S, Jacobsen KK, Ribases M, Bosch R, Sanchez-Mora C, et al. An international multicenter association study of the serotonin transporter gene in persistent ADHD. Genes Brain Behav 2010;9(5):449-58.

[42] Sanchez-Mora C, Ribases M, Ramos-Quiroga JA, Casas M, Bosch R, BoreattiHummer A, et al. Meta-analysis of brain-derived neurotrophic factor p. Val66Met in adult ADHD in four European populations. Am J Med Genet B Neuropsychiatr Genet 2010;153B(2):512-23.

[43] Banerjee TD, Middleton F, Faraone SV. Environmental risk factors for attention-deficit hyperactivity disorder. Acta Paediatr 2007;96(9):1269-74.

[44] Botting N, Powls A, Cooke RW, Marlow N. Attention deficit hyperactivity disorders and other psychiatric outcomes in very low birthweight children at 12 years. JChild PsycholPsychiatry. 1997;38(8):931-41.

[45] Milberger S, Biederman J, Faraone SV, Guite J, Tsuang MT. Pregnancy, delivery and infancy complications and attention deficit hyperactivity disorder: issues of gene-environment interaction. Biol Psychiatry 1997;41(1):65-75.

[46] Cohen MJ, Meador KJ, Browning N, May R, Baker GA, Clayton-Smith J, et al. Fetal antiepileptic drug exposure: adaptive and emotional/behavioral functioning at age 6years. Epilepsy Behav 2013;29(2):308-15.

[47] Gustavson K, Ystrom E, Stoltenberg C, Susser E, Suren P, Magnus P, et al. Smoking in pregnancy and child ADHD. Pediatrics 2017;139(2).

[48] Depue BE, Burgess GC, Bidwell LC, Willcutt EG, Banich MT. Behavioral performance predicts grey matter reductions in the right inferior frontal gyrus in young adults with combined type ADHD. Psychiatry Res 2010;182 (3):231-7.

[49] Pironti VA, Lai MC, Muller U, Dodds CM, Suckling J, Bullmore ET, et al Neuroanatomical abnormalities and cognitive impairments are shared by adults with attention-deficit/hyperactivity disorder and their unaffected first-degree relatives. Biol Psychiatry 2014;76(8):639-47.

[50] Makris N, Seidman LJ, Valera EM, Biederman J, Monuteaux MC, Kennedy DN et al. Anterior cingulate volumetric alterations in treatment-naive adults with ADHD: a pilot study. J Atten Disord 2010;13(4):407-13.

[51] Frodl T, Skokauskas N. Meta-analysis of structural MRI studies in children and adults with attention deficit hyperactivity disorder indicates treatment effects. Acta Psychiatr Scand 2012;125(2):114-26.

[52] Amico F, Stauber J, Koutsouleris N, Frodl T. Anterior cingulate cortex gray matter abnormalities in adults with attention deficit hyperactivity disorder: a voxel-based morphometry study. Psychiatry Res 2011;191(1):31-5.

[53] Seidman LJ, Biederman J, Liang L, Valera EM, Monuteaux MC, Brown A, et al. Gray matter alterations in adults with attention-deficit/hyperactivity disorder identified by voxel based morphometry. Biol Psychiatry 2011;69 (9):857-66.

[54] Almeida Montes LG, Ricardo-Garcell J, Barajas De La Torre LB, Prado Alcantara H, Martinez Garcia RB, Fernandez-Bouzas A, et al. Clinical correlations of grey matter reductions in the caudate nucleus of adults with attention deficit hyperactivity disorder. J Psychiatry Neurosci 2010;35(4):238-46.

[55] Makris N, Liang L, Biederman J, Valera EM, Brown AB, Petty C, et al. Toward defining the neural substrates of ADHD: a controlled structural MRI study in medication-naive adults. J Atten Disord 2015;19(11):944-53.

[56] Proal E, Reiss PT, Klein RG, Mannuzza S, Gotimer K, Ramos-Olazagasti MA et al. Brain gray matter deficits at 33-year follow-up in adults with attentiondeficit/hyperactivity disorder established in childhood. Arch Gen Psychiatry 2011;68(11):1122-34.

[57] Ahrendts J, Rusch N, Wilke M, Philipsen A, Eickhoff SB, Glauche V, et al. Visua cortex abnormalities in adults with ADHD: a structural MRI study. World J Biol Psychiatry 2011;12(4):260-70.

[58] Duerden EG, Tannock R, Dockstader C. Altered cortical morphology in sensorimotor processing regions in adolescents and adults with attentiondeficit/hyperactivity disorder. Brain Res 2012;1445:82-91.

[59] Almeida LG, Ricardo-Garcell J, Prado H, Barajas L, Fernandez-Bouzas A, Avila $D$, et al. Reduced right frontal cortical thickness in children, adolescents and adults with ADHD and its correlation to clinical variables: a cross-sectional study. J Psychiatr Res 2010;44(16):1214-23.

[60] Nakao T, Radua J, Rubia K, Mataix-Cols D. Gray matter volume abnormalities in ADHD: voxel-based meta-analysis exploring the effects of age and stimulant medication. Am J Psychiatry 2011;168(11):1154-63.

[61] Rubia K, Alegria AA, Brinson H. Brain abnormalities in attention-deficit hyperactivity disorder: a review. Rev Neurol (Paris) 2014:58(Suppl 1) S3-16.

[62] Onnink AM, Zwiers MP, Hoogman M, Mostert JC, Kan CC, Buitelaar J, et al Brain alterations in adult ADHD: effects of gender, treatment and comorbid depression. European neuropsychopharmacology: the journal of the European College of Neuropsychopharmacology. 2014;24(3):397-409.

[63] Spencer TJ, Brown A, Seidman LJ, Valera EM, Makris N, Lomedico A, et al. Effect of psychostimulants on brain structure and function in ADHD: a qualitative literature review of magnetic resonance imaging-based neuroimaging studies. J Clin Psychiatry 2013;74(9):902-17.

[64] Hoekzema E, Carmona S, Ramos-Quiroga JA, Richarte Fernandez V, Picado M Bosch R, et al. Laminar thickness alterations in the fronto-parietal cortical mantle of patients with attention-deficit/hyperactivity disorder. PLoS One 2012;7(12)e48286.

[65] Hoogman M, Buitelaar JK, Faraone SV, Shaw P, Franke B, group E-Aw. Subcortical brain volume differences in participants with attention deficit hyperactivity disorder in children and adults - authors' reply. Lancet Psychiatry 2017;4(6):440-1.

[66] Dramsdahl M, Westerhausen R, Haavik J, Hugdahl K, Plessen KJ. Adults with attention-deficit/hyperactivity disorder - a diffusion-tensor imaging study of the corpus callosum. Psychiatry Res 2012;201(2):168-73.
[67] Konrad A, Dielentheis Tf Fau - El Masri D, El Masri D Fau - Dellani PR, Dellani Pr Fau - Stoeter P, Stoeter P Fau - Vucurevic G, Vucurevic G Fau - Winterer G, et al. White matter abnormalities and their impact on attentional performance in adult attention-deficit/hyperactivity disorder. 2012(14338491 (Electronic)).

[68] Cortese S, Imperati D, Zhou J, Proal E, Klein RG, Mannuzza S, et al. White matter alterations at 33-year follow-up in adults with childhood attentiondeficit/hyperactivity disorder. Biol Psychiatry 2013.

[69] Onnink AM, Zwiers MP, Hoogman M, Mostert JC, Dammers J, Kan CC, et al. Deviant white matter structure in adults with attention-deficit/ hyperactivity disorder points to aberrant myelination and affects neuropsychological performance. Prog Neuropsychopharmacol Biol Psychiatry 2015;63:14-22.

[70] Shaw P, Sudre G, Wharton A, Weingart D, Sharp W, Sarlls J. White matter microstructure and the variable adult outcome of childhood attention deficit hyperactivity disorder. Neuropsychopharmacology 2015;40(3):746-54.

[71] Konrad A, Dielentheis TF, El Masri D, Bayerl M, Fehr C, Gesierich T, et al. Disturbed structural connectivity is related to inattention and impulsivity in adult attention deficit hyperactivity disorder. Eur J Neurosci 2010;31 (5):912-9.

[72] van Ewijk H, Heslenfeld DJ, Zwiers MP, Faraone SV, Luman M, Hartman CA, et al. Different mechanisms of white matter abnormalities in attentiondeficit/hyperactivity disorder: a diffusion tensor imaging study. J Am Acad Child Adolesc Psychiatry 2014;53(7) 790-9.e3.

[73] Liston C, Cohen MM, Teslovich T, Levenson D, Casey BJ. Atypical prefrontal connectivity in attention-deficit/hyperactivity disorder: pathway to disease or pathological end point? Biol Psychiatry 2011;69(12):1168-77.

[74] Cortese S, Kelly C, Chabernaud C, Proal E, Di Martino A, Milham MP, et al. Toward systems neuroscience of ADHD: a meta-analysis of 55 fMRI studies. Am J Psychiatry 2012;169(10):1038-55.

[75] Hart H, Radua J, Nakao T, Mataix-Cols D, Rubia K. Meta-analysis of functional magnetic resonance imaging studies of inhibition and attention in attentiondeficit/hyperactivity disorder: exploring task-specific, stimulant medication, and age effects. JAMA Psychiatry 2013;70(2):185-98.

[76] Hart H, Radua J, Mataix-Cols D, Rubia K. Meta-analysis of fMRI studies of timing in attention-deficit hyperactivity disorder (ADHD). Neurosci Biobehav Rev 2012;36(10):2248-56.

[77] Yeo BT, Krienen FM, Sepulcre J, Sabuncu MR, Lashkari D, Hollinshead M, et al. The organization of the human cerebral cortex estimated by intrinsic functional connectivity. J Neurophysiol 2011;106(3):1125-65.

[78] Castellanos FX, Proal E. Large-scale brain systems in ADHD: beyond the prefrontal-striatal model. Trends Cogn Sci (Regul Ed) 2012;16(1):17-26.

[79] Sudre G, Szekely E, Sharp W, Kasparek S, Shaw P. Multimodal mapping of the brain's functional connectivity and the adult outcome of attention deficit hyperactivity disorder. Proc Natl Acad Sci U S A. 2017;114(44):11787-92.

[80] Wasserman T, Wasserman LD. The sensitivity and specificity of neuropsychological tests in the diagnosis of attention deficit hyperactivity disorder. Appl Neuropsychol Child 2012;1(2)90-9, doi:http://dx.doi.org/ 10.1080/21622965.2012.702025 Epub 2012 Jul 10.

[81] Pettersson R, Soderstrom S, Nilsson KW. Diagnosing ADHD in adults: an examination of the discriminative validity of neuropsychological tests and diagnostic assessment instruments. J Atten Disord 2015.

[82] Mostert JC, Onnink AM, Klein M, Dammers J, Harneit A, Schulten T, et al. Cognitive heterogeneity in adult attention deficit/hyperactivity disorder: a systematic analysis of neuropsychological measurements. Eur Neuropsychopharmacol 2015;25(11):2062-74.

[83] Barkley RA, Fischer M. Predicting impairment in major life activities and occupational functioning in hyperactive children as adults: self-reported executive function (EF) deficits versus EF tests. Dev Neuropsychol 2011;36 (2):137-61.

[84] Musso MW, Gouvier WD. Why is this so hard?: A review of detection of malingered ADHD in college students. J Atten Disord 2014;18(6):186-201.

[85] Bekker EM, Overtoom CC, Kenemans JL, Kooij JJ, De Noord I, Buitelaar JK, et al. Stopping and changing in adults with ADHD. Psychol Med 2005;35 (6):807-16.

[86] Bekker EM, Kenemans JL, Hoeksma MR, Talsma D, Verbaten MN. The pure electrophysiology of stopping. Int J Psychophysiol 2005.

[87] Seidman LJ, Valera EM, Bush G. Brain function and structure in adults with attention-deficit/hyperactivity disorder. Psychiatr Clin North Am 2004;27 (2):323-47.

[88] Seidman LJ, Doyle A, Fried R, Valera E, Crum K, Matthews L. Neuropsychological function in adults with attention-deficit/hyperactivity disorder. Psychiatr Clin North Am 2004;27(2):261-82.

[89] Seidman L], Valera EM, Makris N. Structural brain imaging of attentiondeficit/hyperactivity disorder. Biol Psychiatry 2005;57(11):1263-72.

[90] Swanson JM, Elliott GR, Greenhill LL, Wigal T, Arnold LE, Vitiello B, et al. Effects of stimulant medication on growth rates across 3 years in the MTA follow-up. J Am Acad Child Adolesc Psychiatry 2007;46(8):1015-27.

[91] Volkow ND, Wang GJ, Newcorn J, Fowler JS, Telang F, Solanto MV, et al. Brain dopamine transporter levels in treatment and drug naive adults with ADHD. Neuroimage 2007:34(3):1182-90.

[92] Retz W, Klein RG. Attention-deficit hyperactivity disorder (ADHD) in adults. Key issues in mental health. Basel: Karger; 2010.

[93] Snyder SM, Rugino TA, Hornig M, Stein MA. Integration of an EEG biomarker with a clinician's ADHD evaluation. Brain Behav 2015;5(4)e00330, doi:http:// dx.doi.org/10.1002/brb3.330 Epub 2015 Mar 5. 
[94] Arns M, Conners CK, Kraemer HC. A decade of EEG Theta/Beta ratio research in ADHD: a meta-analysis. J Atten Disord 2013;17(5)374-83, doi:http://dx. doi.org/10.1177/1087054712460087 Epub 2012 Oct 19.

[95] Liechti MD, Valko L, Muller UC, Dohnert M, Drechsler R, Steinhausen HC, et al. Diagnostic value of resting electroencephalogram in attentiondeficit/ hyperactivity disorder across the lifespan. Brain Topogr 2013;26 (1) 135-51.

[96] Arns M, Loo SK, Sterman MB, Heinrich H, Kuntsi J, Asherson P, et al. Editorial Perspective: how should child psychologists and psychiatrists interpret FDA device approval? Caveat emptor. J Child Psychol Psychiatry 2016;57 (5):656-8.

[97] Faraone SV, Sergeant J, Gillberg C, Biederman J. The worldwide prevalence of ADHD: is it an American condition? World Psychiatry 2003;2(2):104-13.

[98] Goodheart CD. A primer for ICD-10-CM users: psychological and behavioral conditions. Washington, DC: American Psychological Association; 2014.

[99] Kupfer DJ, Kuhl EA, Wulsin L. Psychiatry's integration with medicine: the role of DSM-5. Annu Rev Med 2013;64:385-92, doi:http://dx.doi.org/10.1146/ annurev-med-050911-161945.

[100] Kooij JJS, Boonstra AM, Swinkels SH, Bekker EM, de Noord I, Buitelaar JK. Reliability, validity, and utility of instruments for self-report and informant report concerning symptoms of ADHD in adult patients. J Atten Disord 2008;11(4):445-58.

[101] Solanto MV, Wasserstein J, Marks DJ, Mitchell KJ. Diagnosis of ADHD in adults: What is the appropriate DSM-5 symptom threshold for hyperactivityimpulsivity? J Atten Disord 2012;16(8):631-4.

[102] Kooij JJ, Buitelaar JK, van den Oord EJ, Furer JW, Rijnders CA, Hodiamont PP. Internal and external validity of attention-deficit hyperactivity disorder in a population-based sample of adults. Psychol Med (Paris) 2005;35(6):817-27.

[103] Barkley RA. Barkley adult ADHD rating Scale-IV (BAARS-IV). New York, NY: Guilford Press; US; 2011.

[104] Skirrow C, Asherson P. Emotional lability, comorbidity and impairment in adults with attention-deficit hyperactivity disorder. J Affect Disord 2013;147 (1-3):80-6.

[105] Brown TE. A new understanding of ADHD in children and adults. New York: Routledge; 2013.

[106] Polanczyk G, Laranjeira R, Zaleski M, Pinsky I, Caetano R, Rohde LA. ADHD in a representative sample of the Brazilian population: estimated prevalence and comparative adequacy of criteria between adolescents and adults according to the item response theory. Int J Methods Psychiatr Res 2010;19 (3):177-84.

[107] Faraone SV, Kunwar A, Adamson J, Biederman J. Personality traits among ADHD adults: implications of late-onset and subthreshold diagnoses. Psychol Med (Paris) 2009;39(4)685-93, doi:http://dx.doi.org/10.1017/ S0033291708003917 Epub 2008 Jun 30.

[108] Chandra S, Biederman J, Faraone SV. Assessing the validity of the age at onset criterion for diagnosing ADHD in DSM-5. J Atten Disord 2016;27:1087054716629717.

[109] Moffitt TE, Houts R, Asherson P, Belsky DW, Corcoran DL, Hammerle M, et al. Is adult ADHD a childhood-onset neurodevelopmental disorder? Evidence from a four-decade longitudinal cohort study. Am J Psychiatry 2015;172 (10):967-77.

[110] Kieling C, Kieling RR, Rohde LA, Frick PJ, Moffitt T, Nigg JT, et al. The age at onset of attention deficit hyperactivity disorder. Am J Psychiatry 2010;167 (1):14-6, doi:http://dx.doi.org/10.1176/appi.ajp.2009.09060796.

[111] Morstedt B, Corbisiero S, Bitto H, Stieglitz RD. Attention-deficit/hyperactivity disorder (ADHD) in adulthood: concordance and differences between selfand informant perspectives on symptoms and functional impairment. PLoS One 2015;10(11)e0141342.

[112] Prevatt F, Proctor B, Best L, Baker L, Van Walker J, Taylor NW. The Positive Illusory Bias: Does it Explain Self-Evaluations in College Students With ADHD? J Atten Disord 2012;16(3):235-43.

[113] APA. Diagnostic and Statistical Manual of Mental Disorders - DSM 5 - 5th ed. Force. APAD-T, editor. Washington, DC: American Psychiatric Publishing; 2013.

[114] Skirrow C, Asherson P. Emotional lability, comorbidity and impairment in adults with attention-deficit hyperactivity disorder. J Affect Disord 2013;147 (1-3):80-6.

[115] Surman CB, Biederman J, Spencer T, Miller CA, McDermott KM, Faraone SV. Understanding deficient emotional self-regulation in adults with attention deficit hyperactivity disorder: a controlled study. Atten Defic Hyperact Disord 2013;5(3):273-81.

[116] Seli P, Smallwood J, Cheyne JA, Smilek D. On the relation of mind wandering and ADHD symptomatology. Psychon Bull Rev 2015;22(3):629-36.

[117] Shaw GA, Giambra L. Task-unrelated thoughts of college students diagnosed as hyperactive in childhood. Dev Neuropsychol 1993;9(1):17-30.

[118] Weyandt LL, Iwaszuk W, Fulton K, Ollerton M, Beatty N, Fouts H, et al. The internal restlessness scale: performance of college students with and without ADHD. J Learn Disabil 2003;36(4):382-9.

[119] Asherson P. Clinical assessment and treatment of attention deficit hyperactivity disorder in adults. Expert Rev Neurother 2005;5(4):525-39.

[120] Mowlem FD, Skirrow C, Reid P, Maltezos S, Nijjar SK, Merwood A, et al. Validation of the mind excessively wandering scale and the relationship of mind wandering to impairment in adult ADHD. J Atten Disord 2016.

[121] Brown TE. ADD/ADHD and impaired executive function in clinical practice. Curr Psychiatry Rep 2008;10(5):407-11.
[122] Barkley RA. Differential diagnosis of adults with ADHD: the role of executive function and self-regulation. J Clin Psychiatry 2010;71(7):e17.

[123] Bijlenga D, Jasperse M, Gehlhaar SK, Sandra Kooij JJ. Objective QbTest and subjective evaluation of stimulant treatment in adult attention deficithyperactivity disorder. Eur Psychiatry 2015;30(1)179-85, doi:http://dx.doi. org/10.1016/j.eurpsy.2014.06.003 Epub Aug 27.

[124] Toplak ME, West RF, Stanovich KE. Practitioner review: do performancebased measures and ratings of executive function assess the same construct? J Child Psychol Psychiatry 2013;54(2):131-43.

[125] Barkley RA, Fischer M. Predicting impairment in major life activities and occupational functioning in hyperactive children as adults: self-reported executive function (EF) deficits versus EF tests. Dev Neuropsychol 2011;36 (2):137-61.

[126] de Graaf R, Kessler RC, Fayyad J, ten Have M, Alonso J, Angermeyer M, et al. The prevalence and effects of adult attention-deficit/hyperactivity disorder (ADHD) on the performance of workers: results from the WHO World Mental Health Survey Initiative. Occup Environ Med 2008;65(12):835-42.

[127] Fredriksen M, Dahl AA, Martinsen EW, Klungsoyr O, Faraone SV, Peleikis DE. Childhood and persistent ADHD symptoms associated with educational failure and long-term occupational disability in adult ADHD. Atten Defic Hyperact Disord 2014;6(2):87-99.

[128] Rogers DC, Dittner AJ, Rimes KA, Chalder T. Fatigue in an adult attention deficit hyperactivity disorder population: a trans-diagnostic approach. Br J Clin Psychol 2017;56(1):33-52.

[129] Altszuler AR, Page TF, Gnagy EM, Coxe S, Arrieta A, Molina BS, et al. Financial dependence of young adults with childhood ADHD. J Abnorm Child Psychol 2016;44(6):1217-29, doi:http://dx.doi.org/10.1007/s10802015-0093-9.

[130] Bielefeld M, Drews M, Putzig I, Bottel L, Steinbuchel T, Dieris-Hirche J, et al. Comorbidity of Internet use disorder and attention deficit hyperactivity disorder: two adult case-control studies. J Behav Addict 2017;6(4):490-504 doi:http://dx.doi.org/10.1556/2006.6.17.073.

[131] Barkley RA, Cox D. A review of driving risks and impairments associated with attention-deficit/hyperactivity disorder and the effects of stimulant medication on driving performance. J Safety Res 2007;38(1):113-28.

[132] Dalsgaard S, Ostergaard SD, Leckman JF, Mortensen PB, Pedersen MG Mortality in children, adolescents, and adults with attention deficit hyperactivity disorder: a nationwide cohort study. Lancet 2015;385 (9983):2190-6.

[133] Chang Z, Quinn PD, Hur K, Gibbons RD, Sjolander A, Larsson H, et al. Association between medication use for Attention-deficit/hyperactivity disorder and risk of motor vehicle crashes. JAMA Psychiatry 2017;74 (6):597-603.

[134] Guendelman MD, Ahmad S, Meza JI, Owens EB, Hinshaw SP. Childhood attention-deficit/hyperactivity disorder predicts intimate partner victimization in young women. J Abnorm Child Psychol 2015.

[135] Buitelaar NJ, Posthumus JA, Buitelaar JK. ADHD in childhood and/or adulthood as a risk factor for domestic violence or intimate partner violence: a systematic review. J Atten Disord 2015;20: (1087054715587099):1087054715587099.

[136] Kaye S, Gilsenan J, Young JT, Carruthers S, Allsop S, Degenhardt L, et al. Risk behaviours among substance use disorder treatment seekers with and without adult ADHD symptoms. Drug Alcohol Depend 2014;144:70-7.

[137] Chang Z, Lichtenstein P, D’Onofrio BM, Almqvist C, Kuja-Halkola R, Sjolander A, et al. Maternal age at childbirth and risk for ADHD in offspring: a population-based cohort study. Int J Epidemiol 2014;43(6)1815-24, doi: http://dx.doi.org/10.1093/ije/dyu204 Epub 2014 Oct 29.

[138] Hosain GM, Berenson AB, Tennen H, Bauer LO, Wu ZH. Attention deficit hyperactivity symptoms and risky sexual behavior in young adult women. Womens Health (Larchmt). 2012;21(4)463-8, doi:http://dx.doi.org/10.1089/ jwh.2011.825 Epub 2 Feb 3.

[139] McClernon FJ, Kollins SH. ADHD and smoking: from genes to brain to behavior. Ann N Y Acad Sci 2008;1141:131-47.

[140] Furczyk K, Thome J. Adult ADHD and suicide. Attent Defic Hyperact Disord. 2014;6(3):153-8.

[141] Swanson EN, Owens EB, Hinshaw SP. Pathways to self-harmful behaviors in young women with and without ADHD: a longitudinal examination of mediating factors. J Child Psychol Psychiatry 2014;55(5)505-15 Epub 2013 Dec 23.

[142] Ginsberg Y, Hirvikoski T, Lindefors N. Attention deficit hyperactivity disorder (ADHD) among longer-term prison inmates is a prevalent, persistent and disabling disorder. BMC Psychiatry 2010;10:112.

[143] Young S, Gudjonsson G, Asherson P, Theobald J, Oliver B, Scott C, et al. Attention deficit hyperactivity disorder and critical incidents in a Scottish prison population. Pers Individ Dif 2009;46:265-9.

[144] Bijlenga D, van der Heijden KB, Breuk M, van Someren EJ, Lie ME, Boonstra AM, et al. Associations between sleep characteristics, seasonal depressive symptoms, lifestyle, and ADHD symptoms in adults. J Atten Disord 2013;17 (3):261-74.

[145] Spencer TJ, Faraone SV, Tarko L, McDermott K, Biederman J. Attention-deficit hyperactivity disorder and adverse health outcomes in adults. J Nerv Ment Dis 2014;202(10):725-31.

[146] Stickley A, Koyanagi A, Takahashi H, Ruchkin V, Inoue Y, Kamio Y. Attentiondeficit/hyperactivity disorder and physical multimorbidity: a populationbased study. Eur Psychiatry 2017;45:227-34. 
[147] Instanes JT, Klungsoyr K, Halmoy A, Fasmer OB, Adult ADHD Haavik ]. Comorbid somatic disease: a systematic literature review. J Atten Disord 2018;22(3):203-28.

[148] Hegvik TA, Instanes JT, Haavik J, Klungsoyr K, Engeland A. Associations between attention-deficit/hyperactivity disorder and autoimmune diseases are modified by sex: a population-based cross-sectional study. Eur Child Adolesc Psychiatry 2017;5(10):017-1056.

[149] Cortese S, Moreira-Maia CR, St Fleur D, Morcillo-Penalver C, Rohde LA, Faraone SV. Association between ADHD and obesity: a systematic review and meta-analysis. Am J Psychiatry 2016;173(1):34-43.

[150] Asherson P, Akehurst R, Kooij JJ, Huss M, Beusterien K, Sasane R, et al. Under diagnosis of adult ADHD: cultural influences and societal burden. J Atten Disord 2012;16(5 Suppl) 20S-38S.

[151] Tegelbeckers J, Bunzeck N, Duzel E, Bonath B, Flechtner HH, Krauel K. Altered salience processing in attention deficit hyperactivity disorder. Hum Brain Mapp 2015;36(6):2049-60.

[152] Bozhilova NS, Michelini G, Kuntsi J, Asherson P. Mind wandering perspective on attention-deficit/hyperactivity disorder. Neurosci Biobehav Rev 2018;92:464-76.

[153] Polanczyk GV, Salum GA, Sugaya LS, Caye A, Rohde LA. Annual Research Review: a meta-analysis of the worldwide prevalence of mental disorders in children and adolescents. J Child Psychol Psychiatry 2015;56(3):345-65.

[154] Wood DR, Reimherr FW, Wender PH, Johnson GE. Diagnosis and treatment of minimal brain dysfunction in adults: a preliminary report. Arch Gen Psychiatry 1976;33(12):1453-60.

[155] Weiss G, Hechtman L, Milroy T. Psychiatric status of hyperactives as adults: a controlled prospective 15-year follow-up of 63 hyperactive children. J Am Acad Child Psychiatry 1985;24:211-20.

[156] Mannuzza S, Klein RG, Addalli KA. Young adult mental status of hyperactive boys and their brothers: a prospective follow-up study. J Am Acad Child Adolesc Psychiatry 1991;30(5):743-51.

[157] Lie N. Follow-ups of children with attention deficit hyperactivity disorder (ADHD). Review of literature. Acta Psychiatr Scand Suppl 1992;368:1-40.

[158] Wender PH, Wolf LE, Wasserstein J. Adults with ADD: an overview. Ann N Y Acad Sci 2001;931(pp 1-16).

[159] Barkley RA, Fischer M, Smallish L, Fletcher K. The persistence of attentiondeficit/hyperactivity disorder into young adulthood as a function of reporting source and definition of disorder. J Abnorm Psychol 2002;111(2):279-89.

[160] Mannuzza S, Klein RG, Moulton 3rd JL. Persistence of Attention-Deficit Hyperactivity Disorder into adulthood: what have we learned from the prospective follow-up studies? J Atten Disord 2003;7(2):93-100.

[161] Asherson P, Chen W, Craddock B, Taylor E. Adult attention-deficit hyperactivity disorder: recognition and treatment in general adult psychiatry. Br J Psychiatry 2007;190:4-5.

[162] Michielsen M, Semeijn E, Comijs HC, van de Ven P, Beekman AT, Deeg DJ, et al. Prevalence of attention-deficit hyperactivity disorder in older adults in the Netherlands. Br J Psychiatry 2012;201(4):298-305.

[163] Michielsen M, de Kruif JT, Comijs HC, van Mierlo S, Semeijn EJ, Beekman AT, et al. The burden of ADHD in older adults: a qualitative study. J Atten Disord 2015.

[164] Semeijn E, Kooij JJS, Comijs H, Michielsen M, Deeg DJ, Beekman AT. Attentiondeficit/hyperactivity disorder, physical health, and lifestyle in older adults. Am Geriatr Soc 2013;61(6):882-7.

[165] Goodman DW, Mitchell S, Rhodewalt L, Surman CB. Clinical presentation, diagnosis and treatment of attention-deficit hyperactivity disorder (ADHD) in older adults: a review of the evidence and its implications for clinical care. Drugs Aging 2016;33(1):27-36.

[166] Torgersen T, Gjervan B, Lensing MB, Rasmussen K. Optimal management of ADHD in older adults. Neuropsychiatr Dis Treat 2016;12:79-87.

[167] Kooij JJ, Michielsen M, Kruithof H, Bijlenga D. ADHD in old age: a review of the literature and proposal for assessment and treatment. Expert Rev Neurother 2016;16(12):1371-81.

[168] Rucklidge JJ. Gender differences in attention-deficit/hyperactivity disorder. Psychiatr Clin North Am 2010;33(2):357-73.

[169] Barkley RA, Murphy KR, Fischer M. ADHD in adults: what the science says. New York: Guildford Press; 2010.

[170] Biederman J, Mick E, Faraone SV, Braaten E, Doyle A, Spencer T, et al. Influence of gender on attention deficit hyperactivity disorder in children referred to a psychiatric clinic. Am J Psychiatry 2002;159(1):36-42.

[171] Vingilis E, Erickson PG, Toplak ME, Kolla NJ, Mann RE, Seeley J, et al. Attention deficit hyperactivity disorder symptoms, comorbidities, substance use, and social outcomes among men and women in a canadian sample. Biomed Res Int 2015;2015:982072.

[172] Quinn PO, Madhoo M. A review of attention-deficit/hyperactivity disorder in women and girls: uncovering this hidden diagnosis. Prim Care Companion CNS Disord 2014;16(3).

[173] Ptacek R, Kuzelova H, Papezova H, Stepankova T. Attention deficit hyperactivity disorder and eating disorders. Prague Med Rep 2010;111 (3):175-81.

[174] Arnett AB, Pennington BF, Willcutt EG, DeFries JC, Olson RK. Sex differences in ADHD symptom severity. J Child Psychol Psychiatry 2015;56(6)632-9, doi: http://dx.doi.org/10.1111/jcpp.12337 Epub 2014 Oct 4.

[175] Argumedo GS, Sanz CR, Olguin HJ. Experimental models of developmental hypothyroidism. Horm Metab Res 2012;44(2)79-85, doi:http://dx.doi.org/ 10.1055/s-0031-1297941 Epub 2011 Dec 27.
[176] Fuller-Thomson E, Lewis DA, Agbeyaka SK. Attention-deficit/hyperactivity disorder casts a long shadow: findings from a population-based study of adult women with self-reported ADHD. Child Care Health Dev 2016;42 (6):918-27.

[177] Van Voorhees EE, Mitchell JT, McClernon FJ, Beckham JC, Kollins SH. Sex, ADHD symptoms, and smoking outcomes: an integrative model. Med Hypotheses 2012;78(5):585-93.

[178] Faraone SV, Biederman J, Mick E. The age-dependent decline of attention deficit hyperactivity disorder: a meta-analysis of follow-up studies. Psychol Med (Paris) 2006;36(2):159-65.

[179] Casey BJ, Jones RM. Neurobiology of the adolescent brain and behavior: implications for substance use disorders. J Am Acad Child Adolesc Psychiatry 2010;49(12)1189-201, doi:http://dx.doi.org/10.1016/j.jaac.2010.08.017 quiz 285, Epub Oct 8.

[180] Singh SP. Transition of care from child to adult mental health services: the great divide. Curr Opin Psychiatry 2009;22(4):386-90, doi:http://dx.doi.org/ 10.1097/YCO.0b013e32832c9221.

[181] While A, Forbes A, Ullman R, Lewis S, Mathes L, Griffiths P. Good practices that address continuity during transition from child to adult care: synthesis of the evidence. Child Care Health Dev 2004;30(5):439-52.

[182] NICE. Attention deficit hyperactivity disorder: diagnosis and management: national Insitute for Health and Care Excellence. 2008.

[183] Nutt DJ, Fone K, Asherson P, Bramble D, Hill P, Matthews K, et al. Evidencebased guidelines for management of attention-deficit/hyperactivity disorder in adolescents in transition to adult services and in adults: recommendations from the British Association for Psychopharmacology. J Psychopharmacol 2007;21(1):10-41.

[184] Bolea-Alamanac B, Nutt DJ, Adamou M, Asherson P, Bazire S, Coghill D, et al. Evidence-based guidelines for the pharmacological management of attention deficit hyperactivity disorder: update on recommendations from the British Association for Psychopharmacology. J Psychopharmacol (Oxford) 2014:28(3):179-203.

[185] Young S, Adamou M, Asherson P, Coghill D, Colley B, Gudjonsson G, et al. Recommendations for the transition of patients with ADHD from child to adult healthcare services: a consensus statement from the UK adult ADHD network. BMC Psychiatry 2016;16(301), doi:http://dx.doi.org/10.1186/ s12888-016-1013-4

[186] Singh SP, Paul M, Ford T, Kramer T, Weaver T, McLaren S, et al. Process, outcome and experience of transition from child to adult mental healthcare: multiperspective study. Br J Psychiatry 2010;197(4):305-12, doi:http://dx. doi.org/10.1192/bjp.bp.109.075135.

[187] Tatlow-Golden M, Gavin B, McNamara N, Singh S, Ford T, Paul M, et al. Transitioning from child and adolescent mental health services with attention-deficit hyperactivity disorder in Ireland: case note review. Early Interv Psychiatry 2017.

[188] McNamara N, McNicholas F, Ford T, Paul M, Gavin B, Coyne I, et al. Transition from child and adolescent to adult mental health services in the Republic of Ireland: an investigation of process and operational practice. Early Interv Psychiatry 2014;8(3)291-7, doi:http://dx.doi.org/10.1111/eip.12073 Epub 2013 Jul 4.

[189] Swift KD, Hall CL, Marimuttu V, Redstone L, Sayal K, Hollis C. Transition to adult mental health services for young people with Attention Deficit/ Hyperactivity Disorder (ADHD): a qualitative analysis of their experiences. BMC Psychiatry 2013;13(74).

[190] Hall CL, Newell K, Taylor J, Sayal K, Hollis C. Services for young people with attention deficit/hyperactivity disorder transitioning from child to adult mental health services: a national survey of mental health trusts in England. J Psychopharmacol (Oxford) 2015;29(1)39-42, doi:http://dx.doi.org/10.1177/ 0269881114550353 Epub 2014 Sep 18.

[191] Coghill D. Services for adults with ADHD: work in progress: commentary on. Specialist adult ADHD clinics in East Anglia. BJPsych Bull. 2015;39(3):140-3, doi:http://dx.doi.org/10.1192/pb.bp.114.048850.

[192] Sibley MH, Rohde LA, Swanson JM, Hechtman LT, Molina BSG, Mitchell JT, et al. Late-onset ADHD reconsidered with comprehensive repeated assessments between ages 10 and 25. Am J Psychiatry 2018;175(2):140-9.

[193] Faraone SV, Biederman J. Can attention-deficit/hyperactivity disorder onset occur in adulthood? JAMA Psychiatry 2016:73(7):655-6.

[194] Caye A, Sibley MH, Swanson JM, Rohde LA. Late-onset ADHD: understanding the evidence and building theoretical frameworks. Curr Psychiatry Rep 2017;19(12):106.

[195] Cooper M, Hammerton G, Collishaw S, Langley K, Thapar A, Dalsgaard S, et al. Investigating late-onset ADHD: a population cohort investigation. J Child Psychol Psychiatry Allied Discip 2018;59(10):1105-13.

[196] Ustun B, Adler LA, Rudin C, Faraone SV, Spencer TJ, Berglund P, et al. The world health organization adult attention-deficit/hyperactivity disorder self-report screening scale for DSM-5. JAMA Psychiatry 2017;74(5):520-6.

[197] NICE. Diagnosis and management of ADHD in children, young people and adults. London The British Psychological Society and The Royal College of Psychiatrists; 2018.

[198] Kooij JJ. Adult ADHD: diagnostic assessment and treatment. 3rd ed. London: Springer; 2013.

[199] Ramos-Quiroga JA, Bosch R, Richarte V, Valero S, Gomez-Barros N, Nogueira $\mathrm{M}$, et al. Criterion and concurrent validity of Conners Adult ADHD Diagnostic Interview for DSM-IV (CAADID) Spanish version. [Spanish] Validez de criterio y concurrente de la version espanola de la Conners Adult 
ADHD Diagnostic Interview for DSM-IV. Rev Psiquiatr Salud Ment 2012:5 (4):229-35.

[200] Rommelse N, van der Kruijs M, Damhuis J, Hoek I, Smeets S, Antshel KM, et al. An evidenced-based perspective on the validity of attention-deficit/ hyperactivity disorder in the context of high intelligence. Neurosci Biobehav Rev 2016;71:21-47.

[201] Jacob CP, Romanos J, Dempfle A, Heine M, Windemuth-Kieselbach C, Kruse A, et al. Co-morbidity of adult attention-deficit/hyperactivity disorder with focus on personality traits and related disorders in a tertiary referral center. Eur Arch Psychiatry Clin Neurosci 2007;257(6)309-17 Epub 2007 Apr 1.

[202] Fayyad J, Sampson NA, Hwang I, Adamowski T, Aguilar-Gaxiola S, AlHamzawi A, et al. The descriptive epidemiology of DSM-IV adult ADHD in the world health organization world mental health surveys. Atten Defic Hyperact Disord 2017;9(1):47-65.

[203] Faraone SV, Asherson P, Banaschewski T, Biederman J, Buitelaar JK, RamosQuiroga JA, et al. Attention-deficit/hyperactivity disorder. Nat Rev Dis Primers 2015;1:15020, doi:http://dx.doi.org/10.1038/nrdp.2015.20.

[204] Roy A, Hechtman L, Arnold LE, Sibley MH, Molina BS, Swanson JM, et al. Childhood factors affecting persistence and desistence of attention-deficit/ hyperactivity disorder symptoms in adulthood: results from the MTA. J Am Acad Child Adolesc Psychiatry 2016;55(11), doi:http://dx.doi.org/10.1016/j. jaac.2016.05.027 937-44.e4, Epub Sep 2.

[205] Instanes JT, Haavik J, Halmoy A. Personality traits and comorbidity in adults with ADHD. J Atten Disord 2016;20(10)845-54, doi:http://dx.doi.org/ 10.1177/1087054713511986 Epub 2013 Nov 22.

[206] Skirrow C, McLoughlin G, Kuntsi J, Asherson P. Behavioral, neurocognitive and treatment overlap between attention-deficit/hyperactivity disorder and mood instability. Expert Rev Neurother 2009;9(4):489-503, doi:http://dx. doi.org/10.1586/ern.09.2.

[207] Corbisiero S, Morstedt B, Bitto H, Stieglitz RD. Emotional dysregulation in adults with attention-deficit/hyperactivity disorder-validity, predictability, severity, and comorbidity. J Clin Psychol 2017;73(1)99-112, doi:http://dx.doi. org/10.1002/jclp.22317 Epub 2016 May 6.

[208] Ferrer M, Andion O, Matali J, Valero S, Navarro JA, Ramos-Quiroga JA, et al. Comorbid attention-deficit/hyperactivity disorder in borderline patients defines an impulsive subtype of borderline personality disorder. J Pers Disord 2010;24(6):812-22.

[209] O’Malley GK, McHugh L, Mac Giollabhui N, Bramham J. Characterizing adult attention-deficit/hyperactivity-disorder and comorbid borderline personality disorder: ADHD symptoms, psychopathology, cognitive functioning and psychosocial factors. Eur Psychiatry 2016;31:29-36, doi: http://dx.doi.org/10.1016/j.eurpsy.2015.09.012 Epub Dec 3.

[210] Van Dijk FE, Lappenschaar M, Kan CC, Verkes RJ, Buitelaar JK. Symptomatic overlap between attention-deficit/hyperactivity disorder and borderline personality disorder in women: the role of temperament and character traits. Compr Psychiatry 2012;53(1):39-47.

[211] Gillberg C. Deficits in attention, motor control, and perception: a brief review. Arch Dis Child 2003;88(10):904-10.

[212] Foreman DM, Foreman D, Prendergast M, Minty B. Is clinic prevalence of ICD-10 hyperkinesis underestimated? Impact of increasing awareness by a questionnaire screen in an UK clinic. Eur Child Adolesc Psychiatry 2001;10(2):130-4.

[213] von Polier GG, Vloet TD, Herpertz-Dahlmann B. ADHD and delinquency-a developmental perspective. Behav Sci Law 2012;30(2):121-39.

[214] Young S, Moss D, Sedgwick O, Fridman M, Hodgkins P. A meta-analysis of the prevalence of attention deficit hyperactivity disorder in incarcerated populations. Psychol Med (Paris) 2015;45(2):247-58.

[215] Young S, Thome J. ADHD and offenders. World J Biol Psychiatry 2011;12 (Suppl 1):124-8.

[216] Young S, Goodwin E. Attention-deficit/hyperactivity disorder in persistent criminal offenders: the need for specialist treatment programs. Expert Rev Neurother 2010;10(10):1497-500, doi:http://dx.doi.org/10.1586/ern.10.142.

[217] D’Amelio R, Retz W, Philipsen A, Rösler M. Psychoedukation und Coaching ADHS im Erwachsenenalter. Manual zur Leitung von Patienten- und Angehörigengruppen. München: Urban \& Fischer Elsevier; 2009.

[218] Hirvikoski T, Waaler E, Lindstrom T, Bolte S, Jokinen J. Cognitive behavior therapy-based psychoeducational groups for adults with ADHD and their significant others (PEGASUS): an open clinical feasibility trial. Atten Defic Hyperact Disord 2015;7(1):89-99.

[219] Hirvikoski T, Lindström T, Carlsson J, Waaler E, Jokinen J, Bölte S. Psychoeducational groups for adults with ADHD and their significant others (PEGASUS): a pragmatic multicenter and randomized controlled trial. Eur Psychiatry 2017;9(44):141-52.

[220] Volkow ND, Swanson JM. Clinical practice: adult attention deficithyperactivity disorder. N Engl J Med 2013;369(20):1935-44.

[221] Bushe C, Day K, Reed V, Karlsdotter K, Berggren L, Pitcher A, et al. A network meta-analysis of atomoxetine and osmotic release oral system methylphenidate in the treatment of attention-deficit/hyperactivity disorder in adult patients. J Psychopharmacol 2016;30(5):444-58.

[222] Cortese S, Adamo N, Del Giovane C, Mohr-Jensen C, Hayes AJ, Carucci S, et al. Comparative efficacy and tolerability of medications for attentiondeficit hyperactivity disorder in children, adolescents, and adults: a systematic review and network meta-analysis. Lancet Psychiatry 2018;5 (9):727-38.

[223] Koesters M, Becker T, Kilian R, Fegert JM, Weinmann S. Limits of metaanalysis: methylphenidate in the treatment of adult attention-deficit hyperactivity disorder. J Psychopharmacol (Oxford) 2009;23(7):733-44.
[224] Faraone SV, Glatt SJ. A comparison of the efficacy of medications for adult attention-deficit/hyperactivity disorder using meta-analysis of effect sizes. J Clin Psychiatry 2010;71(6):754-63.

[225] Castells X, Ramos-Quiroga JA, Rigau D, Bosch R, Nogueira M, Vidal X, et al. Efficacy of methylphenidate for adults with attention-deficit hyperactivity disorder: a meta-regression analysis. CNS Drugs 2011;25(2):157-69.

[226] Castells X, Ramos-Quiroga JA, Bosch R, Nogueira M, Casas M. Amphetamines for attention deficit hyperactivity disorder (ADHD) in adults. Cochrane Database Syst Rev 2011(6) CD007813.

[227] Cunill R, Castells X, Tobias A, Capella D. Atomoxetine for attention deficit hyperactivity disorder in the adulthood: a meta-analysis and metaregression. Pharmacoepidemiol Drug Saf 2013;22(9):961-9.

[228] Philipsen A, Jans T, Graf E, Matthies S, Borel P, Colla M, et al. Effects of group psychotherapy, individual counseling, methylphenidate, and placebo in the treatment of adult Attention-Deficit/Hyperactivity disorder: a randomized clinical trial. JAMA Psychiatry 2015;72(12):1199-210, doi:http://dx.doi.org/ 10.1001/jamapsychiatry.2015.2146.

[229] Chang Z, Lichtenstein P, D'Onofrio BM, Sjolander A, Larsson H. Serious transport accidents in adults with attention-deficit/hyperactivity disorder and the effect of medication: a population-based study. JAMA Psychiatry 2014;71(3):319-25.

[230] Lichtenstein P, Larsson H. Medication for attention deficit-hyperactivity disorder and criminality. N Engl J Med 2013;368(8):776.

[231] Chen Q, Sjolander A, Runeson B, D’Onofrio BM, Lichtenstein P, Larsson H. Drug treatment for attention-deficit/hyperactivity disorder and suicidal behaviour: register based study. BMJ 2014;348:g3769.

[232] Chang Z, D’Onofrio BM, Quinn PD, Lichtenstein P, Larsson H. Medication for attention-deficit/hyperactivity disorder and risk for depression: a nationwide longitudinal cohort study. Biol Psychiatry 2016;80(12): 916-22.

[233] Chang Z, Lichtenstein P, Halldner L, D’Onofrio B, Serlachius E, Fazel S, et al. Stimulant ADHD medication and risk for substance abuse. J Child Psychol Psychiatry Allied Discip 2014;55(8):878-85.

[234] Sharman J, Pennick M. Lisdexamfetamine prodrug activation by peptidasemediated hydrolysis in the cytosol of red blood cells. Neuropsychiatr Dis Treat 2014;10:2275-80.

[235] Setyawan J, Hodgkins P, Guerin A, Gauthier G, Cloutier M, Wu EQ et al. Comparing treatment adherence of lisdexamfetamine and other medications for the treatment of attention deficit/hyperactivity disorder: a retrospective analysis. J Med Econ 2013;16(7):962-75.

[236] Adler LA, Goodman DW, Kollins SH, Weisler RH, Krishnan S, Zhang Y, et al. Double-blind, placebo-controlled study of the efficacy and safety of lisdexamfetamine dimesylate in adults with attention-deficit/hyperactivity disorder. J Clin Psychiatry 2008;69(9):1364-73.

[237] Wigal T, Brams M, Gasior M, Gao J, Squires L, Giblin J, et al. Randomized, double-blind, placebo-controlled, crossover study of the efficacy and safety of lisdexamfetamine dimesylate in adults with attention-deficit/ hyperactivity disorder: novel findings using a simulated adult workplace environment design. Behav Brain Funct 2010;6:34.

[238] Dupaul GJ, Weyandt LL, Rossi JS, Vilardo BA, O’Dell SM, Carson KM, et al. Double-blind, placebo-controlled, crossover study of the efficacy and safety of lisdexamfetamine dimesylate in college students with ADHD. J Atten Disord 2012;16(3):202-20.

[239] Maneeton N, Maneeton B, Suttajit S, Reungyos J, Srisurapanont M, Martin SD. Exploratory meta-analysis on lisdexamfetamine versus placebo in adult ADHD. Drug design. development and therapy. 2014;8:1685-93.

[240] Coghill DR, Caballero B, Sorooshian S, Civil R. A systematic review of the safety of lisdexamfetamine dimesylate. CNS Drugs 2014;28(6):497-511.

[241] Adler LA, Dirks B, Deas PF, Raychaudhuri A, Dauphin MR, Lasser RA, et al Lisdexamfetamine dimesylate in adults with attention-deficit/ hyperactivity disorder who report clinically significant impairment in executive function: results from a randomized, double-blind, placebo-controlled study. J Clin Psychiatry 2013;74(7):694-702.

[242] Epstein T, Patsopoulos NA, Weiser M. Immediate-release methylphenidate for attention deficit hyperactivity disorder (ADHD) in adults. Cochrane Database Syst Rev 2014(9) CD005041.

[243] Martinez-Raga J, Knecht C, Szerman N, Martinez MI. Risk of serious cardiovascular problems with medications for attention-deficit hyperactivity disorder. CNS Drugs 2013;27(1):15-30.

[244] Coghill D, Banaschewski T, Zuddas A, Pelaz A, Gagliano A, Doepfner M. Longacting methylphenidate formulations in the treatment of attention-deficit/ hyperactivity disorder: a systematic review of head-to-head studies. BMC Psychiatry 2013;13:237.

[245] Mick E, McManus DD, Goldberg RJ. Meta-analysis of increased heart rate and blood pressure associated with CNS stimulant treatment of ADHD in adults. European neuropsychopharmacology: the journal of the European College of Neuropsychopharmacology. 2013;23(6):534-41.

[246] Westover AN, Halm EA. Do prescription stimulants increase the risk of adverse cardiovascular events?: a systematic review. BMC Cardiovasc Disord 2012;12:41.

[247] Habel LA, Cooper WO, Sox CM, Chan KA, Fireman BH, Arbogast PG, et al ADHD medications and risk of serious cardiovascular events in young and middle-aged adults. JAMA : J Am Med Assoc 2011;306(24):2673-83.

[248] Schelleman H, Bilker WB, Kimmel SE, Daniel GW, Newcomb C, Guevara JP et al. Methylphenidate and risk of serious cardiovascular events in adults. Am J Psychiatry 2012;169(2):178-85. 
[249] Shin JY, Roughead EE, Park BJ, Pratt NL. Cardiovascular safety of methylphenidate among children and young people with attentiondeficit/hyperactivity disorder (ADHD): nationwide self controlled case series study. BMJ 2016;353:i2550.

[250] Asherson P, Bushe C, Saylor K, Tanaka Y, Deberdt W, Upadhyaya H. Efficacy of atomoxetine in adults with attention deficit hyperactivity disorder: an integrated analysis of the complete database of multicenter placebocontrolled trials. J Psychopharmacol (Oxford) 2014;28(9):837-46.

[251] Asherson P, Young S, Adamou M, Bolea B, Coghill D, Gudjonsson G, et al. Handbook for Attention Deficit Hyperactivity Disorder in Adults. UKAAN, Springer Healthcare Communications; 2013.

[252] Ginsberg Y, Ahlqvist-Rastad J, AM K, Barroso J, Bergquist F, Brodd G, et al. Läkemedel vid adhd - behandlingsrekommendation. Information från Läkemedelsverket 2016;(2):13-23.

[253] Quinn PD, Chang Z, Hur K, Gibbons RD, Lahey BB, Rickert ME, et al. ADHD medication and substance-related problems. Am J Psychiatry 2017;174 (9):877-85.

[254] Adler LA, Liebowitz M, Kronenberger W, Qiao M, Rubin R, Hollandbeck M et al. Atomoxetine treatment in adults with attention-deficit/hyperactivity disorder and comorbid social anxiety disorder. Depress Anxiety 2009;26 (3):212-21.

[255] Bangs ME, Emslie GJ, Spencer TJ, Ramsey JL, Carlson C, Bartky EJ, et al. Efficacy and safety of atomoxetine in adolescents with attention-deficit/hyperactivity disorder and major depression. J Child Adolesc Psychopharmacol 2007;17 (4):407-20.

[256] Posey DJ, McDougle CJ. Guanfacine and guanfacine extended release: treatment for ADHD and related disorders. CNS Drug Rev 2007;13(4):465-74.

[257] Huss M, Chen W, Ludolph AG. Guanfacine extended release: a new pharmacological treatment option in Europe. Clin Drug Investig 2016;36 (1):1-25.

[258] Butterfield ME, Saal J, Young B, Young JL. Supplementary guanfacine hydrochloride as a treatment of attention deficit hyperactivity disorder in adults: a double blind, placebo-controlled study. Psychiatry Res 2016;236:136-41.

[259] Kollins SH, Jain R, Brams M, Segal S, Findling RL, Wigal SB, et al. Clonidine extended-release tablets as add-on therapy to psychostimulants in children and adolescents with ADHD. Pediatrics 2011;127(6) e1406-13.

[260] Jain R, Segal S, Kollins SH, Khayrallah M. Clonidine extended-release tablets for pediatric patients with attention-deficit/hyperactivity disorder. J Am Acad Child Adolesc Psychiatry 2011;50(2):171-9.

[261] Palumbo DR, Sallee FR, Pelham Jr. WE, Bukstein OG, Daviss WB, McDermott MP. Clonidine for attention-deficit/hyperactivity disorder: I. Efficacy and tolerability outcomes. J Am Acad Child Adolesc Psychiatry 2008;47(2):180-8.

[262] Hazell PL, Stuart JE. A randomized controlled trial of clonidine added to psychostimulant medication for hyperactive and aggressive children. J Am Acad Child Adolesc Psychiatry 2003;42(8):886-94.

[263] Maneeton N, Maneeton B, Intaprasert S, Woottiluk P. A systematic review of randomized controlled trials of bupropion versus methylphenidate in the treatment of attention-deficit/hyperactivity disorder. Neuropsychiatr Dis Treat 2014;10:1439-49.

[264] Hamedi M, Mohammdi M, Ghaleiha A, Keshavarzi Z, Jafarnia M, Keramatfar R, et al. Bupropion in adults with attention-deficit/hyperactivity disorder: a randomized, double-blind study. Acta Med Iran 2014;52(9):675-80.

[265] Ghanizadeh A. A systematic review of reboxetine for treating patients with attention deficit hyperactivity disorder. Nord J Psychiatry 2015;69(4):241-8.

[266] Riahi F, Tehrani-Doost M, Shahrivar Z, Alaghband-Rad J. Efficacy of reboxetine in adults with attention-deficit/hyperactivity disorder: a randomized, placebo-controlled clinical trial. Hum Psychopharmacol 2010;25(7-8):570-6.

[267] Otasowie J, Castells X, Ehimare UP, Smith CH. Tricyclic antidepressants for attention deficit hyperactivity disorder (ADHD) in children and adolescents. Cochrane Database Syst Rev 2014(9) CD006997.

[268] Prince JB, Wilens TE, Biederman J, Spencer TJ, Millstein R, Polisner DA, et al. A controlled study of nortriptyline in children and adolescents with attention deficit hyperactivity disorder. J Child Adolesc Psychopharmacol 2000;10 (3):193-204.

[269] Weiss M, Hechtman L, Adult ARG. A randomized double-blind trial of paroxetine and/or dextroamphetamine and problem-focused therapy for attention-deficit/hyperactivity disorder in adults. J Clin Psychiatry 2006;67 (4):611-9.

[270] Arnold VK, Feifel D, Earl CQ, Yang R, Adler LA. A 9-week, randomized, doubleblind, placebo-controlled, parallel-group, dose-finding study to evaluate the efficacy and safety of modafinil as treatment for adults with ADHD. J Atten Disord 2014;18(2):133-44.

[271] Wang GJ, Volkow ND, Wigal T, Kollins SH, Newcorn JH, Telang F, et al. Longterm stimulant treatment affects brain dopamine transporter level in patients with attention deficit hyperactive disorder. PLoS One 2013;8(5) e63023.

[272] Cavero I, Guillon JM. Safety pharmacology assessment of drugs with biased 5HT(2B) receptor agonism mediating cardiac valvulopathy. J Pharmacol Toxicol Methods 2014;69(2):150-61.

[273] Droogmans S, Kerkhove D, Cosyns B, Van Camp G. Role of echocardiography in toxic heart valvulopathy. Eur J Echocardiogr 2009;10(4):467-76.

[274] Seixas M, Weiss M, Muller U. Systematic review of national and internationa guidelines on attention-deficit hyperactivity disorder. J Psychopharmacol (Oxford) 2012;26(6):753-65.
[275] Sobanski E, Bruggemann D, Alm B, Kern S, Deschner M, Schubert T, et al. Psychiatric comorbidity and functional impairment in a clinically referred sample of adults with attention-deficit/hyperactivity disorder (ADHD). Eur Arch Psychiatry Clin Neurosci 2007;257(7):371-7.

[276] Sharma A, Couture J. A review of the pathophysiology, etiology, and treatment of attention-deficit hyperactivity disorder (ADHD). Ann Pharmacother 2014;48(2):209-25.

[277] Bazire S. Psychotropic drug directory 2010. Aberdeen: HealthComm UK Ltd; 2010.

[278] Viktorin A, Ryden E, Thase ME, Chang Z, Lundholm C, D’Onofrio BM, et al. The risk of treatment-emergent mania with methylphenidate in bipolar disorder. Am J Psychiatry 2016 appiajp201616040467.

[279] Cunill R, Castells X, Tobias A, Capella D. Pharmacological treatment of attention deficit hyperactivity disorder with co-morbid drug dependence. J Psychopharmacol 2015;29(1):15-23.

[280] Steinhausen HC, Bisgaard C. Substance use disorders in association with attention-deficit/hyperactivity disorder, co-morbid mental disorders, and medication in a nationwide sample. Eur Neuropsychopharmacol 2014;24 (2):232-41.

[281] Levin FR, Mariani JJ, Specker S, Mooney M, Mahony A, Brooks DJ, et al. Extended-release mixed amphetamine salts vs placebo for comorbid adult Attention-Deficit/Hyperactivity disorder and cocaine use disorder: a randomized clinical trial. JAMA Psychiatry 2015;72(6):593-602.

[282] Konstenius M, Jayaram-Lindstrom N, Guterstam J, Beck O, Philips B, Franck J. Methylphenidate for attention deficit hyperactivity disorder and drug relapse in criminal offenders with substance dependence: a 24-week randomized placebo-controlled trial. Addiction 2014;109(3):440-9.

[283] Skoglund C, Brandt L, Almqvist C, D’Onofrio BM, Konstenius M, Franck J, et al. Factors associated with adherence to methylphenidate treatment in adult patients with attention-deficit/hyperactivity disorder and substance use disorders. J Clin Psychopharmacol 2016;36(3):222-8.

[284] Perez de los Cobos J, Sinol N, Perez V, Trujols J. Pharmacological and clinical dilemmas of prescribing in co-morbid adult attention-deficit/hyperactivity disorder and addiction. Br J Clin Pharmacol 2014;77(2):337-56.

[285] Crunelle CL, van den Brink W, Moggi F, Konstenius M, Franck J, Levin FR, et al. International consensus statement on screening, diagnosis and treatment of substance use disorder patients with comorbid attention Deficit/ Hyperactivity disorder. Eur Addict Res 2018;24(1):43-51.

[286] Torgersen T, Gjervan B, Rasmussen K, Vaaler A, Nordahl HM. Prevalence of comorbid substance use disorder during long-term central stimulant treatment in adult ADHD. Adhd Atten Deficit Hyperact Disord 2013;5(1):59-67.

[287] Klassen LJ, Bilkey TS, Katzman M, Chokka P. Comorbid attention Deficit/ Hyperactivity disorder and substance use disorder: treatment considerations. Curr Drug Abuse Rev 2012.

[288] Cheung CH, Frazier-Wood AC, Asherson P, Rijsdijk F, Kuntsi J. Shared cognitive impairments and aetiology in ADHD symptoms and reading difficulties. PLoS One 2014;9(6)e98590.

[289] Rabiner DL, Anastopoulos AD, Costello EJ, Hoyle RH, McCabe SE, Swartzwelder HS. The misuse and diversion of prescribed ADHD medications by college students. J Atten Disord 2009;13(2):144-53.

[290] Besag FM. ADHD treatment and pregnancy. Drug Saf: Int J Med Toxicol Drug Exp 2014;37(6):397-408.

[291] Dideriksen D, Pottegard A, Hallas J, Aagaard L, Damkier P. First trimester in utero exposure to methylphenidate. Basic Clin Pharmacol Toxicol 2013;112 (2):73-6.

[292] Pottegård A, Hallas J, Andersen JT, Løkkegaard EC, Dideriksen D, Aagaard L, et al. First-trimester exposure to methylphenidate: a population-based cohort study. J Clin Psychiatry 2014;75(1):e88-93.

[293] Huybrechts KF, Broms G, Christensen LB, Einarsdottir K, Engeland A, Furu K, et al. Association between methylphenidate and amphetamine use in pregnancy and risk of congenital malformations: a cohort study from the international pregnancy safety study consortium. JAMA Psychiatry 2018;75 (2):167-75

[294] Diav-Citrin O, Shechtman S, Arnon J, Wajnberg R, Borisch C, Beck E, et al. Methylphenidate in pregnancy: a multicenter, prospective, comparative, observational study. J Clin Psychiatry 2016;77(9):1176-81.

[295] Bro SP, Kjaersgaard MI, Parner ET, Sorensen MJ, Olsen J, Bech BH, et al. Adverse pregnancy outcomes after exposure to methylphenidate or atomoxetine during pregnancy. Clin Epidemiol 2015;7:139-47.

[296] Haervig KB, Mortensen LH, Hansen AV, Strandberg-Larsen K. Use of ADHD medication during pregnancy from 1999 to 2010: a Danish register-based study. Pharmacoepidemiol Drug Saf 2014;23(5):526-33.

[297] McAllister-Williams RH, Baldwin DS, Cantwell R, Easter A, Gilvarry E, Glover $\mathrm{V}$, et al. British Association for Psychopharmacology consensus guidance on the use of psychotropic medication preconception, in pregnancy and postpartum 2017. J Psychopharmacol 2017;31(5):519-52.

[298] Bolea-Alamanac BM, Green A, Verma G, Maxwell P, Davies SJ. Methylphenidate use in pregnancy and lactation: a systematic review of evidence. Br J Clin Pharmacol 2014;77(1):96-101.

[299] Larsen ER, Damkier P, Pedersen LH, Fenger-Gron J, Mikkelsen RL, Nielsen RE, et al. Use of psychotropic drugs during pregnancy and breast-feeding. Acta Psychiatr Scand Suppl 2015;445:1-28.

[300] Freeman MP. ADHD and pregnancy. Am J Psychiatry 2014;171(7):723-8.

[301] Atomoxetine [Internet]. U.S. National Library of Medicine. Date accessed: 22.10.2017. Available from: http://toxnet.nlm.nih.gov/cgi-bin/sis/search2/r? dbs+lactmed:@term+@DOCNO+826. 
[302] Guanfacine [Internet]. U.S. National Library of Medicine. Date accessed: 22.10.2017. Available from: http://toxnet.nlm.nih.gov/cgi-bin/sis/search2/r? dbs+lactmed:@term+@DOCNO+631.

[303] Clonidine [Internet]. U.S. National Library of Medicine. Date accessed: 22.10.2017. Available from: http://toxnet.nlm.nih.gov/cgi-bin/sis/search2/r? dbs+lactmed:@term+@DOCNO+73.

[304] Lisdexamfetamine [Internet]. U.S. National Library of Medicine. Date accessed: 22.10.2017. Available from: http://toxnet.nlm.nih.gov/cgi-bin/sis/ search2/r?dbs+lactmed:@term+@DOCNO+834.

[305] Bupropion [Internet]. U.S. National Library of Medicine. Date accessed: 22.10.2017. Available from: http://toxnet.nlm.nih.gov/cgi-bin/sis/search2/r? dbs+lactmed:@term+@DOCNO+321.

[306] Van der Heijden KB, Smits MG, Van Someren EJ, Gunning WB. Idiopathic chronic sleep onset insomnia in attention-deficit/hyperactivity disorder: a circadian rhythm sleep disorder. Chronobiol Int 2005;22(3):559-70.

[307] van Veen MM, Kooij JJ, Boonstra AM, Gordijn MC, van Someren EJ. Delayed circadian rhythm in adults with attention-deficit/hyperactivity disorder and chronic sleep-onset insomnia. Biol Psychiatry 2010;67(11):1091-6.

[308] Kooij JJ, Bijlenga D. The circadian rhythm in adult attention-deficit/hyperactivity disorder: current state of affairs. Exp Rev Neurother. 2013;13(10):1107-16.

[309] Kidwell KM, Van Dyk TR, Lundahl A, Nelson TD. Stimulant medications and sleep for youth with ADHD: a meta-analysis. Pediatrics 2015;136(6):1144-53.

[310] Snitselaar MA, Smits MG, van der Heijden KB, Spijker J. Sleep and circadian rhythmicity in adult ADHD and the effect of stimulants. J Atten Disord 2017:21(1):14-26.

[311] Barrett JR, Tracy DK, Giaroli G. To sleep or not to sleep: a systematic review of the literature of pharmacological treatments of insomnia in children and adolescents with attention-deficit/hyperactivity disorder. J Child Adolesc Psychopharmacol 2013;23(10):640-7.

[312] Van der Heijden KB, Smits MG, Van Someren EJW, Ridderinkhof KR, Gunning WB. Effect of melatonin on sleep, behavior, and cognition in ADHD and chronic sleep-onset insomnia. J Am Acad Child Adolesc Psychiatry 2007;46 (2):233-41.

[313] Hirvikoski T, Waaler E, Alfredsson J, Pihlgren C, Holmstrom A, Johnson A, et al. Reduced ADHD symptoms in adults with ADHD after structured skills training group: results from a randomized controlled trial. Behav Res Ther 2011;49(3):175-85

[314] Young S, Emilsson B, Sigurdsson JF, Khondoker M, Philipp-Wiegmann F, Baldursson $G$, et al. A randomized controlled trial reporting functional outcomes of cognitive-behavioural therapy in medication-treated adults with ADHD and comorbid psychopathology. Eur Arch Psychiatry Clin Neurosci 2017;267(3):267-76.

[315] Jensen CM, Amdisen BL, Jorgensen KJ, Arnfred SM. Cognitive behavioural therapy for ADHD in adults: systematic review and meta-analyses. Atten Defic Hyperact Disord 2016;8(1)3-11, doi:http://dx.doi.org/10.1007/s12402016-0188-3 Epub 2016 Jan 22.

[316] Arnold LE, Hodgkins P, Caci H, Kahle J, Young S. Effect of treatment modality on long-term outcomes in attention-deficit/hyperactivity disorder: a systematic review. PLoS One 2015;10(2)e0116407, doi:http://dx.doi.org/ 10.1371/journal.pone eCollection 2015.

[317] Philipsen A. Psychotherapy in adult attention deficit hyperactivity disorder: implications for treatment and research. Expert rev. 2012;12(10):1217-25.

[318] Mongia M, Hechtman L. Cognitive behavior therapy for adults with attentiondeficit/hyperactivity disorder: a review of recent randomized controlled trials. Curr Psychiatry Rep 2012;14(5):561-7.

[319] Safren SA, Otto MW, Sprich S, Winett CL, Wilens TE, Biederman J. Cognitivebehavioral therapy for ADHD in medication-treated adults with continued symptoms. Behav Res Ther 2005;43(7):831-42.

[320] Safren SA, Sprich S, Mimiaga MJ, Surman C, Knouse L, Groves M, et al. Cognitive behavioral therapy vs relaxation with educational support for medication-treated adults with ADHD and persistent symptoms: a randomized controlled trial. JAMA 2010;304(8):875-80.

[321] Young S, Khondoker M, Emilsson B, Sigurdsson JF, Philipp-Wiegmann F, Baldursson G, et al. Cognitive-behavioural therapy in medication-treated adults with attention-deficit/hyperactivity disorder and co-morbid psychopathology: a randomized controlled trial using multi-level analysis. Psychol Med (Paris) 2015;45(13)2793-804, doi:http://dx.doi.org/10.1017/ S0033291715000756 Epub 2015 May 29.

[322] Emilsson B, Gudjonsson G, Sigurdsson JF, Baldursson G, Einarsson E, Olafsdottir $\mathrm{H}$, et al. Cognitive behaviour therapy in medication-treated adults with ADHD and persistent Symptoms: a randomized controlled trial. BMC Psychiatry 2011;11(116).

[323] Young S, Bramham J. Cognitive-behavioural therapy for ADHD in adolescents and adults: a psychological guide to practice. 2nd edition ed Chichester: John Wiley \& Sons Ltd; 2012.

[324] Knouse LE, Safren SA. Current status of cognitive behavioral therapy for adult attention-deficit hyperactivity disorder. Psychiatric Clin North Am 2010;33 (3):497-509.

[325] Newark PE, Stieglitz RD. Therapy-relevant factors in adult ADHD from a cognitive behavioural perspective. Atten Defic Hyperact Disord 2010;2(2):59-72.

[326] Torrente F, Lopez P, Alvarez Prado D, Kichic R, Cetkovich-Bakmas M, Lischinsky A, et al. Dysfunctional cognitions and their emotional, behavioral, and functional correlates in adults with attention deficit hyperactivity disorder (ADHD): is the cognitive-behavioral model valid? J Atten Disord 2014;18(5)412-24, doi:http://dx.doi.org/10.1177/1087054712443153 Epub 2012 May 24.
[327] Kubik JA. Efficacy of ADHD coaching for adults with ADHD. J Atten Disord 2010;13(5)442-53, doi:http://dx.doi.org/10.1177/1087054708329960 Epub 2009 Mar 10.

[328] Prevatt F, Yelland S. An empirical evaluation of ADHD coaching in college students. J Atten Disord 2015;19(8)666-77, doi:http://dx.doi.org/10.1177/ 1087054713480036 Epub 2013 Mar 18.

[329] Hepark S, Janssen L, de Vries A, Schoenberg PL, Donders R, Kan CC, et al. The efficacy of adapted MBCT on core symptoms and executive functioning in adults with ADHD: a preliminary randomized controlled trial. J Atten Disord 2015;20:1087054715613587.

[330] Schoenberg PL, Hepark S, Kan CC, Barendregt HP, Buitelaar JK, Speckens AE. Effects of mindfulness-based cognitive therapy on neurophysiological correlates of performance monitoring in adult attention-deficit/ hyperactivity disorder. Clin Neurophysiol 2014;125(7):1407-16.

[331] Cairncross M, Miller CJ. The effectiveness of mindfulness-based therapies for ADHD: a meta-analytic review. J Atten Disord 2016.

[332] Braun S, Zeidler J, Linder R, Engel S, Verheyen F, Greiner W. Treatment costs of attention deficit hyperactivity disorder in Germany. Eur J Health Econ 2013;14(6):939-45.

[333] Swensen A, Birnbaum HG, Ben Hamadi R, Greenberg P, Cremieux PY, Secnik K. Incidence and costs of accidents among attention-deficit/hyperactivity disorder patients. J Adolesc Health 2004;35(4)346 e1-9.

[334] Birnbaum HG, Kessler RC, Lowe SW, Secnik K, Greenberg PE, Leong SA, et al. Costs of attention deficit-hyperactivity disorder (ADHD) in the US: excess costs of persons with ADHD and their family members in 2000. Curr Med Res Opin 2005;21(2):195-206.

[335] Marchetti A, Magar R, Lau H, Murphy EL, Jensen PS, Conners CK, et al Pharmacotherapies for attention-deficit/hyperactivity disorder: expectedcost analysis. Clin Ther 2001;23(11):1904-21.

[336] Matza LS, Paramore C, Prasad M. A review of the economic burden of ADHD. Cost effectiveness and resource allocation: C/E. 2005;3:5.

[337] Daley D, Jacobsen RH, Lange AM, Sørensen A. Walldorf J. Costing adult attention deficit hyperactivity disorder. New York: Oxford University Press; 2015.

[338] Fredriksen M, Halmoy A, Faraone SV, Haavik J. Long-term efficacy and safety of treatment with stimulants and atomoxetine in adult ADHD: a review of controlled and naturalistic studies. Eur Neuropsychopharmacol 2013;23 (6):508-27.

[339] Gilmore A, Milne R. Methylphenidate in children with hyperactivity: review and cost-utility analysis. Pharmacoepidemiol Drug Saf 2001;10(2):85-94.

[340] King S, Griffin S, Hodges Z, Weatherly H, Asseburg C, Richardson G, et al. A systematic review and economic model of the effectiveness and costeffectiveness of methylphenidate, dexamfetamine and atomoxetine for the treatment of attention deficit hyperactivity disorder in children and adolescents. Health Technol Assess (Rockv) 2006;10(23) iii-iv, xiii-146.

[341] Narayan S, Hay J. Cost effectiveness of methylphenidate versus AMP/DEX mixed salts for the first-line treatment of ADHD. Expert Rev Pharmacoecon Outcomes Res 2004;4(6):625-34.

[342] Zupancic J, Miller A, Raina P, Lee S, Klassen A, Olsen L. Part 3: economic evaluation of pharmaceutical and psychological/behavioural therapies for attention-deficit hyperactivity disorde. In: Miller A, Lee SK, Raina P, editors. Review of therapies for attention-deficit/hyperactivity disorde. Ottawa, Canada: Canadian Coordinating Office for Health Technology Assessment; 1998.

[343] Donnelly M, Haby MM, Carter R, Andrews G, Vos T. Cost-effectiveness of dexamphetamine and methylphenidate for the treatment of childhood attention deficit hyperactivity disorder. Aust N Z J Psychiatry 2004;38 (8):592-601.

[344] Wu EQ, Hodgkins P, Ben-Hamadi R, Setyawan J, Xie J, Sikirica V, et al. Cost effectiveness of pharmacotherapies for attention-deficit hyperactivity disorder: a systematic literature review. CNS Drugs 2012;26(7):581-600.

[345] Lebowitz MS. Stigmatization of ADHD: a developmental review. J Atten Disord 2016;20(3):199-205.

[346] Baeyens D, Moniquet A, Danckaerts M, van der Oord S. [A comparative study of the structural stigmatisation of ADHD and autism spectrum disorder in Flemish newspapers]. Tijdschr Psychiatr 2017;59(5):269-77.

[347] Corrigan PW, Shapiro JR. Measuring the impact of programs that challenge the public stigma of mental illness. Clin Psychol Rev 2010;30(8):907-22.

[348] Mueller AK, Fuermaier ABM, Koerts J, Tucha L. Stigma in attention deficit hyperactivity disorder. Atten Defic Hyperact Disord 2012;4(3):101-14.

[349] McKeague L, Hennessy E, O’Driscoll C, Heary C. Retrospective accounts of selfstigma experienced by young people with attention-deficit/hyperactivity disorder (ADHD) or depression. Psychiatr Rehabil J 2015;38(2):158-63.

[350] Fuermaier AB, Tucha L, Mueller AK, Koerts J, Hauser J, Lange KW, et al Stigmatization in teachers towards adults with attention deficit hyperactivity disorder. Springerplus 2014;3:26.

[351] Tatlow-Golden M, Prihodova L, Gavin B, Cullen W, McNicholas F. What do general practitioners know about ADHD? Attitudes and knowledge among first-contact gatekeepers: systematic narrative review. BMC Fam Pract 2016;17(1):129.

[352] Brohan E, Henderson C, Wheat $K$, Malcolm E, Clement S, Barley EA, et al Systematic review of beliefs, behaviours and influencing factors associated with disclosure of a mental health problem in the workplace. BMC Psychiatry 2012;12:11.

[353] CADDRA. Canadian ADHD practice guidelines. third edition Toronto, ON: Canadian Attention Deficit Hyperactivity Disorder Resource Alliance; 2011. 